Portland State University

PDXScholar

$5-21-1986$

\title{
The Effect of Order of Presentation and Experience on Problem Solving
}

Edward Bruce Versteeg

Portland State University

Follow this and additional works at: https://pdxscholar.library.pdx.edu/open_access_etds

Part of the Psychology Commons

Let us know how access to this document benefits you.

\section{Recommended Citation}

Versteeg, Edward Bruce, "The Effect of Order of Presentation and Experience on Problem Solving" (1986). Dissertations and Theses. Paper 3689.

https://doi.org/10.15760/etd.5573

This Thesis is brought to you for free and open access. It has been accepted for inclusion in Dissertations and Theses by an authorized administrator of PDXScholar. Please contact us if we can make this document more accessible: pdxscholar@pdx.edu. 
AN ABSTRACT OF THE THESIS OF Edward Bruce Versteeg for the Master of Science in Psychology presented May 21, 1986.

Title: The Effect of Order of Presentation and Experience on Problem Solving.

APPROVED BY MEMBERS OF THE THESIS COMMITTEE:

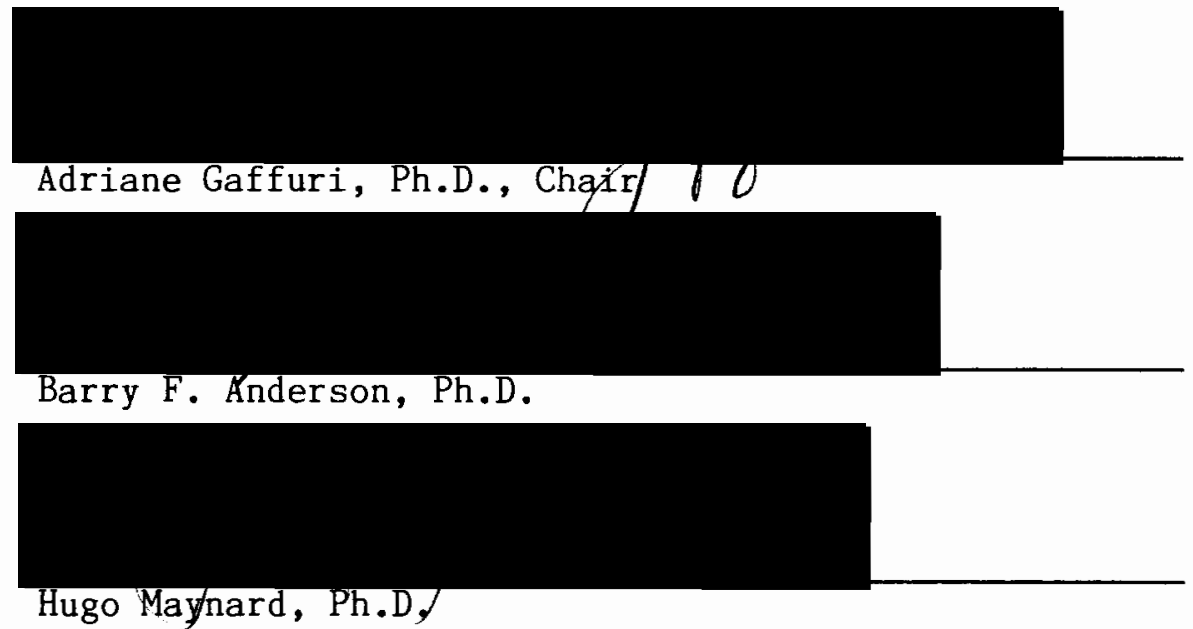

The effects of order of presentation and amount of experience on errors and solution time were investigated. An interactive narrative puzzle was presented on a computer screen to 60 undergraduate students. Solution of the problem involved the integration of two path segments. Subjects in the Forward Condition were presented the path segments in the order in which they had to be traversed for solution. Subjects in the Backward Condition were exposed to the opposite order of presentation. Amount of experience was varied by permitting one, three, or five readings of the narrative. 
The results supported the literature to date suggesting that given a moderate amount of exposure (three trials) to a problem component, people form a imaginal representation of the stimulus which facilitates solution. In addition, the Backward order of presentation of the problem components was more conducive to this strategy. With both minimal exposure and with extensive exposure the Forward order of presentation produced fewer errors. The results were consistent and significant in terms of both number of errors and solution times associated with the six treatment conditions. 
THE EFFECT OF ORDER OF PRESENTATION AND EXPERIENCE ON PROBLEM SOLVING

by

EDWARD BRUCE VERSTEEG

A thesis submitted in partial fulfillment of the requirements for the degree of

\author{
MASTER OF SCIENCE \\ in \\ PSYCHOLOGY
}

Portland State University

1986 
TO THE OFFICE OF GRADUATE STUDIES AND RESEARCH:

The members of the Committee approve the thesis of Edward Bruce Versteeg presented May 21, 1986.

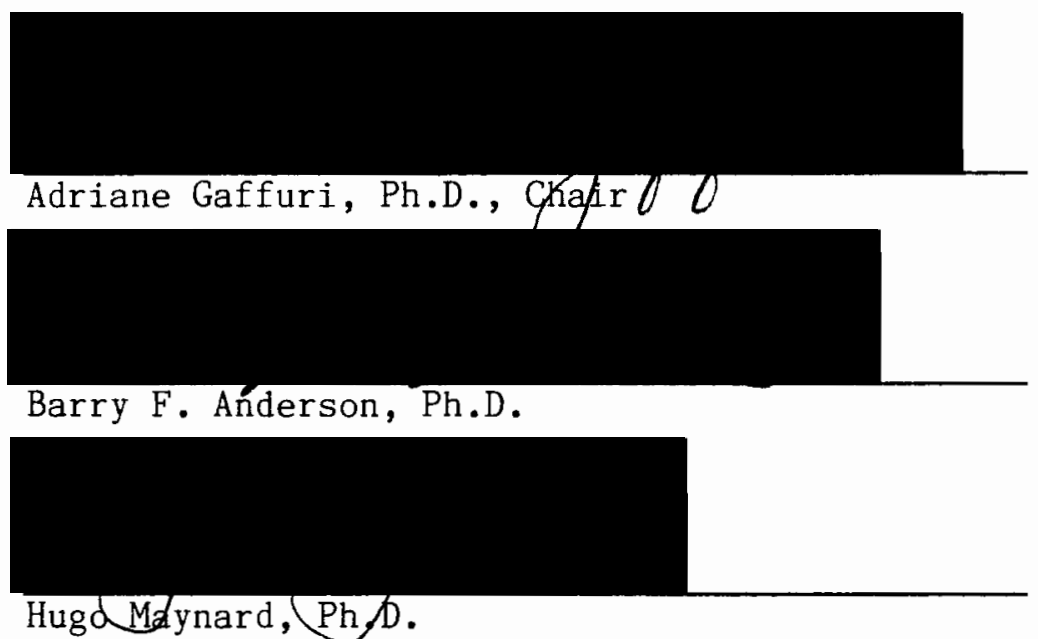

APPROVED:

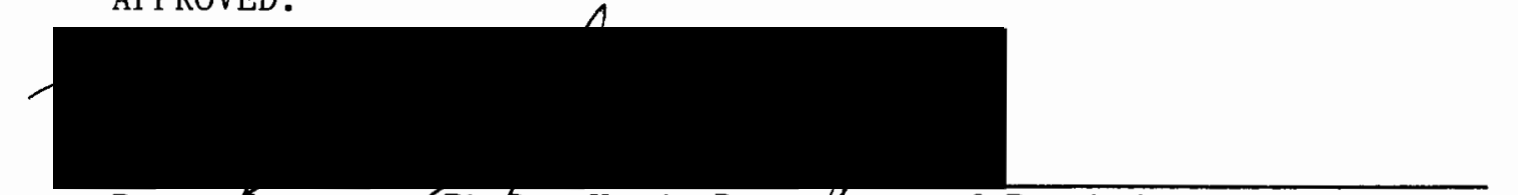

Roger/Jennings, Ph,D., Head, Deparfment of Psychology

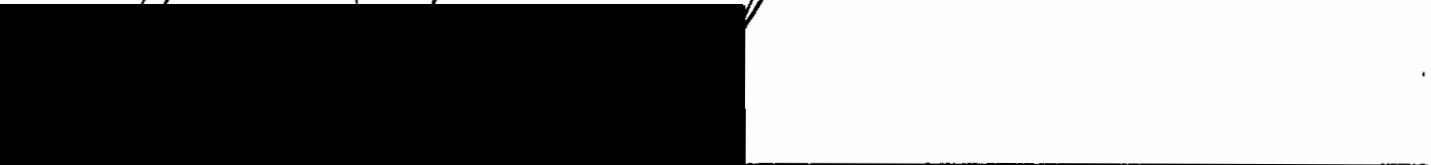

Bernard Ross, Ph.D., Dean of Graduate Studies and Research 


\section{ACKNOWLEDGEMENTS}

It is to my parents and my wife that this thesis is dedicated. I acknowledge the unending support, pride, and love that only parents can provide, and I am truly appreciative that I am their son. I am also blessed by being the recipient and of Polly's love (and thankful of the serendipity of being wedded to a great "proofer").

Special appreciation goes to my committee members: Adriane Gaffuri, for the warmth of her support and prudential guidance, allowing me the latitude to express my ideas without consternation while providing the needed criticism; Barry Anderson, for his wisdom, creativity, and exuberance; and, Hugo Maynard, for his sharing the talent of adhering to the rigors of scientific pursuits without sacrificing personal agendas and feelings, and doing so with the generosity and kindness that is uniquely his. 


\section{TABLE OF CONTENTS}

CHAPTER

I INTRODUCTION $. \ldots \ldots \ldots \ldots \ldots \ldots \ldots \ldots \ldots \ldots \ldots \ldots \ldots, 1$

Order of Presentation..................... 1

Experience........................... 6

Interaction of Order of Presentation and Experience 10

Present Study......................... 11

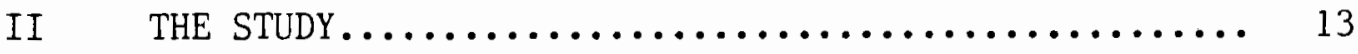

Method.............................. 13

Design

Subjects

Apparatus

Procedure

Pilot Study

Results................................

Errors

Time

Pilot Study

Summary of results

III DISCUSSION.............................. 21

REFERENCES.................................... 25

APPENDIX $1, \ldots \ldots \ldots \ldots \ldots \ldots \ldots \ldots \ldots \ldots \ldots \ldots \ldots \ldots \ldots \ldots \ldots \ldots \ldots \ldots, 28$

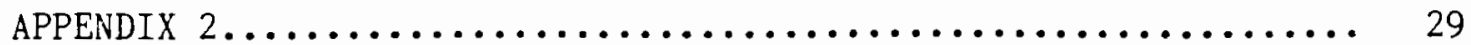

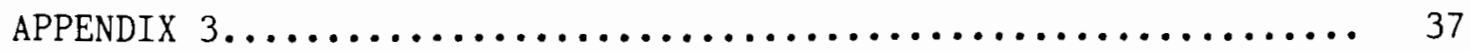




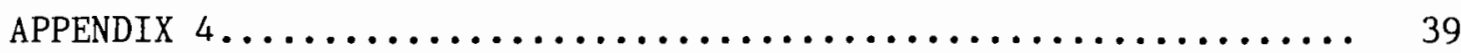

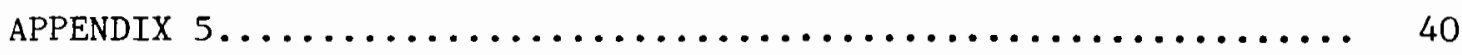

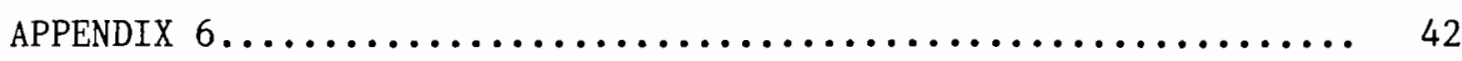

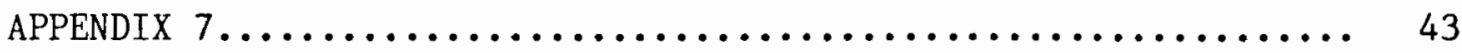

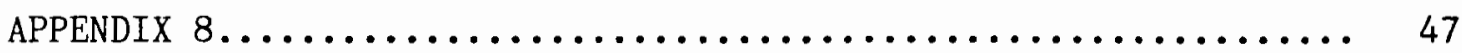

APPENDIX $9 \ldots \ldots \ldots \ldots \ldots \ldots \ldots \ldots \ldots \ldots \ldots \ldots \ldots \ldots \ldots \ldots \ldots \ldots$

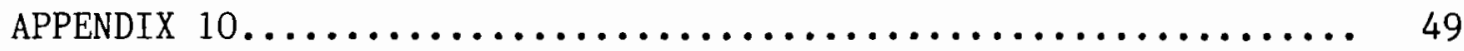




\section{LIST OF FIGURES}

FIGURE

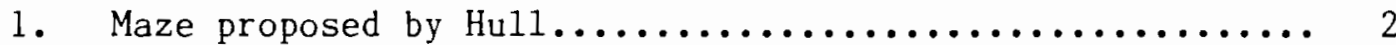

2. Maze used by Versteeg......................... 3

3. Graphs highlighting the similarity between the interactive patterns of both measures (A2) ....... 17

4. Graphs highlighting the similarity between the

interactive patterns of both measures (Al)........ 19 


\section{CHAPTER I}

\section{INTRODUCTION}

This paper is concerned with the effects of order of presentation and amount of experience on reasoning. Problem solution is influenced by the order in which data are presented and the amount of experience of the subject. The relationship of these two factors to problem solution will be developed, first as independent factors, and then in their interaction with one another. Finally, a research design will be presented that examines the pattern of interaction of order of presentation and experience in a problem solving situation.

\section{Order of Presentation}

Work on the topic seems to have begun with Maier (1929) and Hull (1935). Hull (1935) sought to account for the assembly of novel response sequences by rats within the framework of $S-R$ theory. According to his account, during the acquisition of a habit segment, the subject acquires a fractional detachable antedating goal response $\left(r_{g}\right)$ appropriate to the goal object, in addition to the overt response. Utilizing a modified and conventionalized graphic representation of a maze devised originally by Maier (1929), Hull outlined the following response sequences, describing the mechanism of their assembly in terms of S-R tendencies (See Figure 1).

According to Hull's sequence, a hungry rat, with repeated exposure to pathway $W_{1}-F$, will learn to anticipate food when placed in 
compartment $W_{1}$. This same animal is also exposed to pathways $S-W_{1}$ and S- $W_{2}$ when thirsty. With continued exposure, compartment $W_{1}$ and its pathway will not only elicit $\mathrm{r}_{\mathrm{g}}$ drinking appropriate to the water reward as will $W_{2}$, but also $r_{g}$ eating apppropriate to the goal box $F$.

In the problem situation the rat is placed in S hungry. The direct route, $S-F$, is blocked at $\underline{b}$ leaving the rat with options $S-W_{1}$ and $S-W_{2}$. Hull predicted that the animal would select pathway $S-W_{1}$, since the response of running down path $S-W_{1}$ was associated with both the $r_{g}$ for eating and the $r_{g}$ for drinking, whereas the response for running down path $S-W_{2}$ was associated only with the $r_{g}$ for drinking.

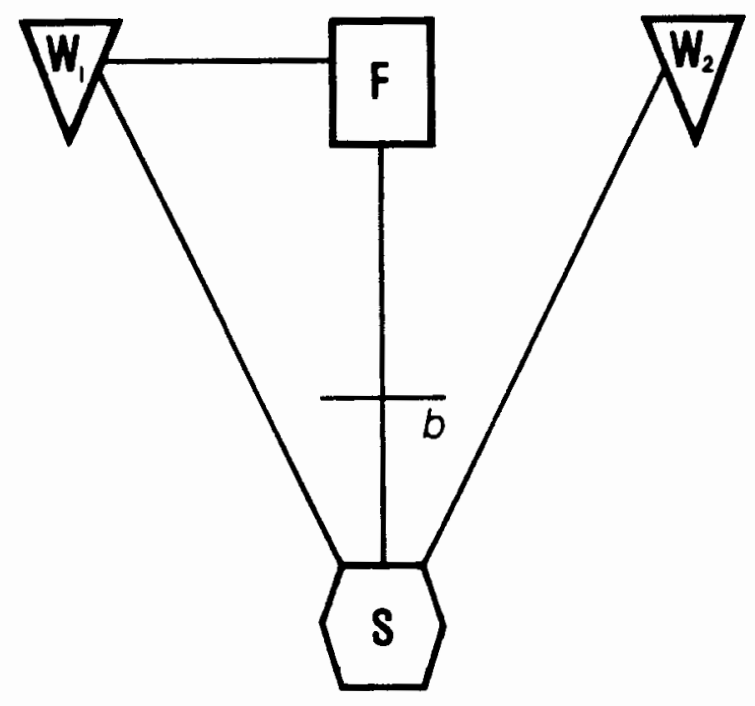

Figure 1. Maze proposed by Hul1.

Osgood (1953) observed that one prediction that derives from Hull's explanation is that the segments, or components, must be learned in the backward order, the component nearer the goal being learned before that farther from the goal. This is necessary in order to permit the fractional antedating goal response, which begins at the goal, to move back to the start where the "reasoning" takes place. 
In a preliminary experiment, the author tested the ability of rats to combine discrete components and utilize that assembly in the solution of a novel problem. The order with which these components were presented directly affected the rats' performances in the problem situation. In a problem similar to the one suggested by Hu11, rats trained in the backward order out-performed rats trained in a forward order condition $(p<.05)$. The maze was modified to be perfectly symmetrical from the Start Box axis, whereas Hull's and Maier's was not (See Figure 2 representing maze modificatiors) (Versteeg, unpublished manusript).

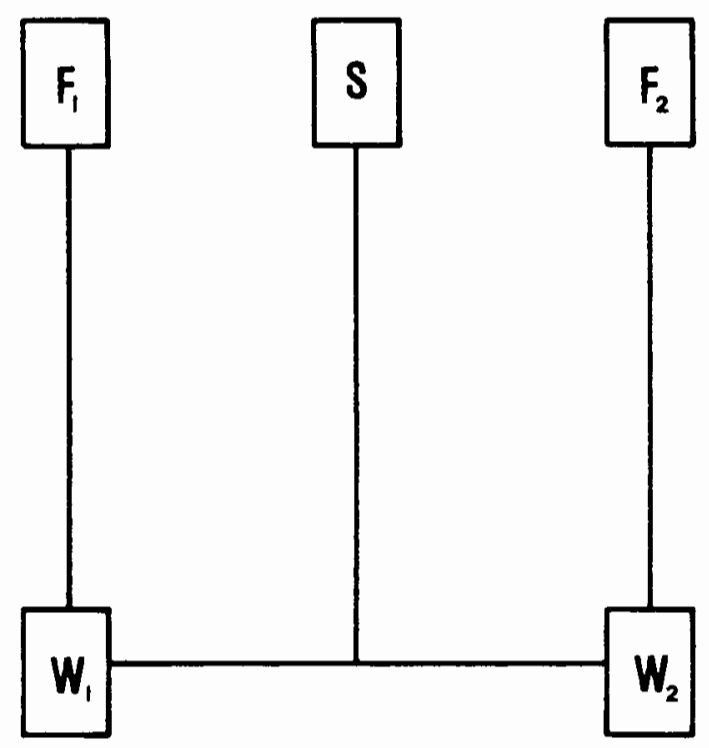

Figure 2. Maze used by Versteeg.

Kendler and Kendler (1961) tested Osgood's prediction and found no difference between forward and backward orders. However, their subjects were children who were beginning to achieve some control over verbal processes, which may have influenced the results. Verbal processes facilitate the representation and organization of data. The 
effect of these capacities and their relationship to problems of seriation will be discussed later.

Perhaps nowhere has the debate involving the influence of order of presentation been more lively than in the arena of relational inferences. For instance, when dealing with three-term series problems, is it easier to combine, $A$ is greater than $B$, and $B$ is greater than $C$, in that order or in the reverse order, $B$ is greater than $C$, followed by, A is greater than B? Support for the former comes from DeSoto, London, and Handel (1965) and Hunter (1957), while support for the latter was produced by Clark (1969 a,b) and Huttenlocher (1968). The two approaches involved are the Image theory (DeSoto, et al., 1965) and the Linguistic theory (Clark, 1969 b), respectively. The fundamental contrast between these competing theories lies in the representation of the premises. The Image theory assumes that the two premises are combined into a unified representation of the three items; the Linguistic theory assumes that information about the items is stored separately. DeSoto found subjects made fewer errors when solving three-term series problems presented in the order A is greater than $B$, and $B$ is greater than $C$ (subsequent1y referred to as the Forward order of presentation). In contrast, Clark found subjects made fewer errors when the series of premises were presented as $B$ is greater than $C$, and $A$ is greater than $B$ (subsequently referred to as the Backward order).

Wason and Johnson-Laird (1972) have suggested a possible resolution of these discrepant theories and findings. They suggest that something like images are used early in practice when the subject is trying to get an overall understanding of the problem, but that 
later, when she knows exactly what is required in the situation, the process becomes automatized in terms of something like a shorthand linguistic representation. One fact that supports this interpretation is that DeSoto's subjects, judging by the number of errors they made, seem to have been less practiced than Clark's. Findings consistent with this hypothesis were reported by Wood in his doctoral thesis (1969) and reported by Wason and Johnson-Laird (1972, p.122). This possibility will be considered fully in the section on interaction of order of presentation and experience.

Shaver, Pierson, and Lang (1975) studied the significance of imagery in problem solving from the perspective of Clark's postulated linguistic principles and Huttenlocher's and DeSoto's visual-spatial imagery postulations. Shaver, et al., report two experiments in which three different classes of operations are brought to bear on the problem: (1) Manipulation of stimulus attributes (characteristics of problens), (2) manipulation of variables that selectively encourage or inhibit the use of imagery (facilitating instructions; the suppression of visualization by reading), and (3) measurement of relevant individual differences (spatial-reasoning ability).

They presented premises and questions both auditorily and visually. Three different relations (spatial, social, and hair color) were presented in the form of linear syllogisms. The three types of relations differed in difficulty, spatial being the easiest to handle, social more difficult, and hair-color most difficult. Reading presentation proved more difficult than listening. This latter finding is well supported by Driesen (1977) using a comparable design focusing on syllogistic reasoning. 
Dreisen explained the better performance associated with stimuli presented auditorily as being related to competition between sensory modalities. Reading interferes with the organization of the premises into visual-spatial imagery. He inferred that the solution seemed dependent on the manipulation of images. Neuropsychological evidence provided additional support for an image theory. Luria (1973) described patients with lesions of the parieto-occipital region of the dominant hemisphere, a region adjoining the visual association area. They could not find their bearings within a system of spatial coordinates, and they could no longer distinguish right from left.

Luria's findings would seem to support the idea that reasoning is spatial in form, as his patients with parieto-occipital lesions of the dominant hemisphere associated with spatial processing lost the ability to reason logically.

\section{Experience}

The assembly of data, or problem components, to meet a goal criterion involves skills, whether they are as simple as remembering which way to turn in a maze or as complicated as composing an algorithm for a computational task. The solution to a problem most of ten rests on the cultivation of new skills. Fitts (1964) has identified three stages of skill development: a cognitive stage, an associative stage, and an automatization stage.

The cognitive stage depends heavily on the verbal executive system, the high-order cognitive processor which is central to achieving abstraction and independence from the environment. It is during this stage that instructions and demonstrations are the most helpful (Fitts, 1964). 
The rules and goals of the task become known and information is organized into short sequences of items, a process known as "chunking" (Miller, 1956). The associative stage describes the period in which internal representation of the relationships of these data chunks crystalize and are available for manipulation or sorting.

It has been indicated that verbal memory images are particularly well suited for retaining information about the serial order of events (Paivio \& Csapo, 1969). Early in serial learning, items in a list seem to be bound together by pairwise associations. However, later in serial learning, items appear to be located within some overall pattern rather than bound to one another. Late in learning, transfer is greater to a list that preserves item positionality as opposed to item pairing, indicating that some sort of spatial representation has been accomplished (Young, 1962; Youssef, 1967). It seems as though this spatial organization serves as a kind of "glue" to hold features together.

A study that ties together the problems involving relational inferences with the problems of seriation described above is provided by Trabasso (1975). In the examination of strategies of transitive inference, the subject is repeatedly shown the adjacent pairs of a series of different length sticks, $A>B, B>C, C>D, D>E$, each stick identifiable by its color. The data suggest that, in the course of these presentations, the subject gradually constructs from these adjacent pairs an internal, possibly image-like representation of the entire ordered array $\mathrm{A}>\mathrm{B}>\mathrm{C}>\mathrm{D}>\mathrm{E}$.

When then asked to compare a pair of lengths he has never seen together before, e.g., B and D, the subject does not work out the 
answer through a step-by-step process of logical inference. Rather, he simply "reads" B > D off his internal representation, much as though the five sticks were all lined up in order of length before his eyes. If logical inference were the solution process, questions about the relative lengths of widely-seperated pairs that had never been experienced, e.g., B ? D or B ? E, should certainly take longer to answer than questions about pairs that are adjacent and had been previously experienced, e.g., A ? B or C ? D. But if the solution process were akin to comparing lengths perceptually, the opposite should be true since, for example, $A$ and $D$ are more different in length and are farther apart in the subject's internal A ... E linear representation than are say $B$ and C. Trabasso (1975) found that the opposite is, in fact, true: the farther away one length is from another in the A ... E series, the shorter the solution time. It is harder to achieve this sort of quasi-spatial internal representation in preschool children than older subjects, e.g., more presentations of the adjacent pairs are required. Once achieved, however, preschool children can solve transitive inference problems, and they appear to solve them in the very same, essentially noninferential fashion (suggestive of an Image process akin to that described by DeSoto above). Previously, investigators, such as Kendler and Kendler (1961) noted above, had not found that children this young could solve transitive inference problems.

As experience with a task increases, we move from the associative stage where stimuli are being translated into associative representation, into the automatization stage (Fitts, 1964). This is, of course, true of our activities in daily living; responses, "...because 
of the great deal of early practice devoted to them, have become largely automatized" (Anderson, 1975, p. 169). This process seems to be true of all mature organisms. Rats tested early in training show place learning while rats tested late in learning show response learning (Restle, 1957).

Thus, what tends to be in the central processor/short-term memory (CP/STM) are environmental goals, e.g., where in the maze the food is located, rather than what particular responses to make to get there. As a consequence of repeated practice, however, the behavior becomes automatized. Instead of being guided by a test-operate-test-exit (TOTE) process toward distant goals in external memory (EM) or STM that require the attention of CP, large series of responses are now elicited by immediately preceding conditions, either in the environment or in the response system, itself. The practiced rat leaves the start box and initiates a sequence of responses that will, with very little attention, take him to the correct goal box, thus leaving CP/STM free for, perhaps, happier thoughts about the food itself (Anderson, 1975, p. 169).

To summarize, it seems that one of the most important, though neglected, independent variables in a cognitive task is the amount of experience the subject has in the problem situation. As experience increases we expect to see subjects follow the transitions through the stages delineated by Fitts. Initially, the problem-solver orients him/herself to the situation, processing instructions, looking for patterns, developing strategies, and perhaps developing partial images (Fitts, 1964). Next, the problem-solver begins forming a representation of the problem parts into whole images (Young, 1962; Youssef, 1967; Trabasso, 1975). After a good deal of experience with the problem situation, the problem-solver develops more economical and efficient strategies, such as non-image coding, and performance becomes automitized (Wood, 1969). 
Interaction of Order of Presentation and Experience

Wood (1969) used series problems involving up to six premises and giving rise to many different types of array. All the premises involved the comparative term taller; and the question was always of the form "who is taller X or Y?" A typical problem was:
(1) D is taller than E
(2) C is taller than D
(3) A is taller than C
(4) A is taller than B
(5) $B$ is taller than $C$
Who is taller B or E?

Wood predicted that subjects would initially solve such problems after the fashion of DeSoto's Image theory: they would build up an internal representation of the items. However, he suspected that with experience they would develop a more sophisticated strategy.

After a subject had solved a certain number of conventional problems, he would be given a special test problem in which, having answered the main question, he would be asked a further unexpected question such as "who is taller A or D?" These supplementary questions were so formed that they could be readily answered only by those subjects who had formed a unified representation of the premises. By varying the number of conventional problems encountered before the test problem, Wood was able to confirm that subjects began by using the representational strategy but rapidly abandoned it in favor ofmore specialized non-representational procedures. What was particularly striking was the rapidity of this development. He found the biggest drop in the ability to answer the supplementary question was from 
those subjects who had previously encountered two conventional problems to those who had previously encountered three.

The effect of practice is probably to induce a more "mechanized" approach to the problem, which minimizes effort and which is appropriate to the particular constraints of the material. At the same time, such an approach is likely to be less flexible and may make it harder to solve an unexpectedly novel type of problem.

Some people seem to discover the imagery technique only after practice with several problems. Johnson-Laird was thus correct to argue that we "can no longer ask how an individual solves a three-term series problem without asking when in his intellectual development within the experiment it was given to him" (Wason and Johnson-Laird, $1972, \mathrm{p} .128)$.

It seems that the forward order of presentation is preferable when subjects are naive and are involved in a sort of cognitive orienting operation. When the components are bound by direct antedating associations, working from the goal toward the givens seems to be preferable. The apparent corollary is that with some experience with a situation, such as the three-term series problem or the maze problem, the backward order should be more facilitative. However, with considerable experience, responses seem to become automatized and this should favor the forward order of presentation.

\section{The present study}

In the present experiment subjects are presented a narrative game that involves two distinct components and are then placed in a test situation which requires synthesis of the parts. Experience with the parts and their order of presentation is manipulated. Three hypo- 
theses are to be tested. First, with minimal exposure to the story, there will be poor performance, but subjects will be more successful with the forward presentation. Secondly, with moderate experience, there will be fewer errors, faster reaction times, and greater success with backward presentation. Finally, with extended exposure to the story, performance is more rapid, with little-to-no errors, and discernably higher performance with those subjects given the forward modality.

In other words, a shift in strategy, much like that suggested by Wood (1969), is expected to occur. Namely, the subject will benefit from a forward order of presentation initially, as he/she orients to the situation. The forward order is less likely to lead to confusion as the problem unfolds simply because in the test situation the parts are presented in the same fashion, thus facilitating recall of "chunks" of data. After some experience with the problem parts, the subjects encountering those parts in a backward order will be better able to assemble a unified representation and will benefit from this strategy (this moderate experience treatment condition coincides with Wood's subjects encountering one or two conventional problem(s) prior to the supplementary problem). Finally, the task demands become automatized with extended experience (coinciding with Wood's subjects experiencing three or more conventional problems). Like Wood's subjects, those encountering the forward order of presentation will be better able to shift strategies and will be more likely to benefit from this flexibility. 
CHAPTER II

THE STUDY

\section{Method}

Design. Two independent variables, Order (Forward, Backward) and Experience (Minimal, Moderate, and High) were varied factorially to create six experimental conditions.

Subjects. Subjects were obtained through undergraduate psychology courses where, after a brief explanation of the study and its purpose to the class, volunteers were solicited. Informed Consent was obtained prior to actual involvement (see Appendix 1). Ten undergraduate students were randomly assigned to each of the six conditions, for a total of 60 subjects.

Apparatus. The narration game was presented on a ten inch monochromatic computer monitor, and responses to story demands were indicated via the keyboard of an Apple IIc computer. The narrative game was written in AppleSoft Basic by the author (see Appendix 2 for the computer program).

Procedure. Subjects in the forward order of presentation were given Part $A$ of the story line to read and respond to first, and subsequently given Part $B$ with its corresponding choice of responses second (see Appendix 3). Subjects in the Backward order of presentation were given Part B followed by Part A. Amount of exposure to the components (Parts A and $B$ ) varied as follows: one reading for the minimal condition, three readings for the moderate condition, and 
five readings for the high experience condition. When the subject had completed the number of readings assigned, he/she was presented once again with the story's Introduction, but then was given the problem (or test) situation, i.e., incorporating both vignettes. The time to solution and the number of errors made during the test situation served as measures of performance.

Pilot Study. A preliminary study, (subsequently referred to as Experiment Al), was conducted. Subjects were solicited in the same manner, and with the same attention to protection of the rights of the participants as described above for the main study, (subsequent1y referred to as Experiment A2). The procedure of execution and data co1lection was the same as that of Experiment A2. In the pilot study a directed debriefing interview was done on completion of the subject's task (see Appendix 4). The amount of experience included one, two, three, and five readings (trials). An equal number of subjects was assigned to both Forward and Backward conditions. Therefore, there were eight conditions with four subjects randomly assigned to each condition $(\mathrm{N}=32)$. An inspection of the data revealed that the "twotrial" condition did not appreciably add to the pattern of interaction between the independent variables, and was deleted from Experiment A2. No further revisions were made, consequently the main study being reported here is essentially identical with the exception of the elimination of the Two-Trial Condition.

\section{$\underline{\text { Results }}$}

There were seven points in the story at which the subject had to choose directions. Therefore, the maximum number of errors was 
seven. Errors ranged from zero to $\operatorname{six}(N=60, \bar{X}=1)$. Following the story's Introduction (see Appendix 2), time recording of the subject's performance began with the presentation of the first vignette. The number of seconds the subjects took to complete the problem ranged from 89 to $195(\mathrm{~N}=60, \bar{X}=128 \mathrm{sec})$. (See Appendix 5 for subject data.)

Figure 3 presents the means for the number of errors and time to solution for each condition as a function of order of presentation and experience.

Errors. Because there was concern about violating the assumptions of the parametric statistics, due to the skewness of the error scores, both parametric and nonparametric tests were performed. Both showed the same pattern of significance. The interaction between the two treatment variables, i.e., order of presentation and amount of experience with the parts of the problem, was significant for errors $(\underline{F}(2,54)=7.41, \underline{p}<.01)$. The Forward group made fewer errors than the Backward group after one practice trial. A t-test for two independent means indicated that this difference was significant (Group $F 1, \bar{X}=2.2$, s.d. $=1.14$, s.d.=1.14; Group B1, $\bar{X}=3.6$, s.d. $=1.43 ; \underline{t}=2.39, \mathrm{df}=18$, $\mathrm{p}$.05). The Backward group made fewer errors than the Forward group with three practice trials. A t-test for two independent means indicated that this difference was also significant (Group B3, $\bar{X}=0.6$, s.d.=0.97; Group F3, $\bar{X}=1.8$, s.d. $=1.48 ; t=2.13, d f=18, p<.05)$. Finally, the Forward group tended to do better after five practice trials. A t-test for two independent means indicated that this difference was marginally significant (Group F5, $\bar{X}=0.0$, s.d.=0.0; Group B5, $\bar{X}=0.3$, s.d. $=0.67 ; \underline{t}=1.42, \mathrm{~d} f=18, \mathrm{p}<0.1)$. A ceiling effect 
may explain why this difference was not very significant; most subjects in both groups made no errors.

Time. The pattern of interaction between the two treatment variables, i.e., order of presentation and amount of experience with the parts of the problem, was also significant for time to solution $\left(\underline{F}(2,54)=3.51, p^{<.05)}\right.$. There was high variability in the time scores (as indicated by the standard deviations). There was no real difference between the Forward and Backward groups in the Low experience condition. A t-test for two independent means was insignificant for this condition. However, the Backward group showed significantly faster times to reach the solution after three trials. A t-test for two independent means indicated that this difference was significant (Group B3, $\bar{X}=123.4$, s.d. $=15.65 ;$ Group F3, $\bar{X}=139.4$, s.d.=18.52; $t=2.17$, $\mathrm{df}=18, \mathrm{p}<.05)$. The Forward Group showed significantly faster times after five trials. A t-test for two independent means indicated that this difference was also significant (Group F5, $\bar{X}=100.7$, s.d.=8.97; Group B5, $\bar{X}=124.8$, s.d.=27.11; $t=2.65, d f=18, \underline{p}<.05$ ). (See Appendix 6 for a complete review of descriptive statistics).

Figure 3 highlights the similarity in the crossover in performance, as measured by both dependent variables (errors and time), as a function of order of presentation and experience (see Appendix 7 for a complete review of the parametric and nonparametric statistics). 

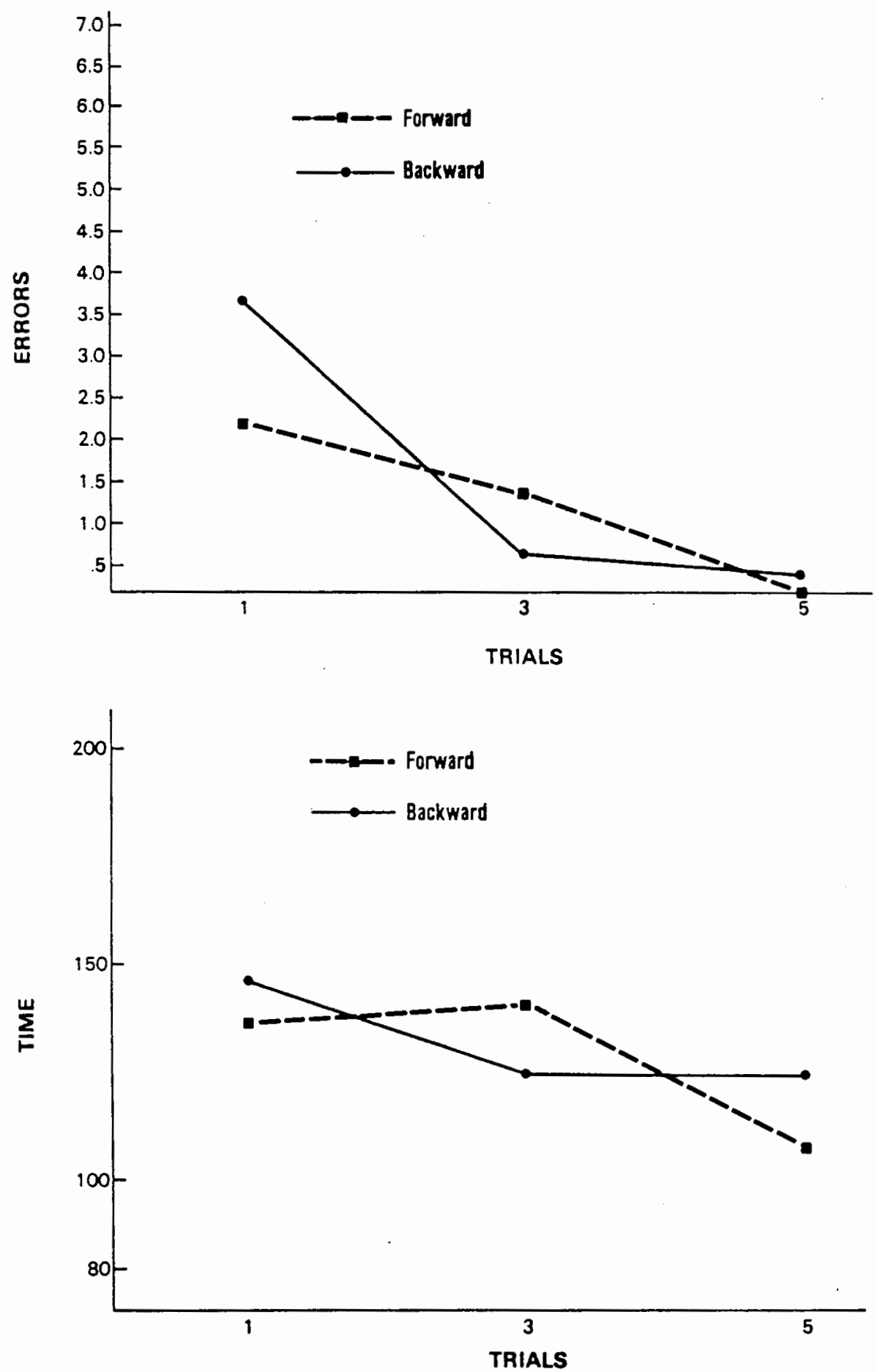

Figure 3. Graphs highlighting the similarity between the interactive patterns of both measures (A2). 
Pilot Study. Further support for this pattern of interaction was found in the results of Experiment Al (pilot study). A relatively large sample size was used in Experiment $A 1 \quad(N=32)$ (see Appendix 8 for Al data), and differed with the subsequent study (A2) only in the elimination of the two-trial experience level. Confidence in the reliablility of the interactive pattern was further enhanced.

Figure 4 highlights the similarity in the crossover in performance in the pilot study, as measured by both dependent variables (errors and time), as a function of order of presentation and experience. There is a striking similarity of this crossover pattern with the pattern for A2 (Figure 3).

The interaction between the two treatment variables, i.e., order of presentation and amount of experience with the parts of the problem, was significant $\left(\underline{F}_{(2,24)}=2.41, \underline{p}<.05\right)$ for the number of errors in Experiment Al. However, the interaction between the two treatment variables was insignificant with regard to time to solution as measured by both parametric, as well as, nonparametric tests (see Appendix 9 for the descpriptive statistics; see Appendix 10 for a complete review of the parametric and nonparametric statistics for A1).

The Backward group in Experiment Al showed significantly fewer errors after three trials. A t-test for two independent means indicated that this difference was significant (Group B3, $\overline{\mathrm{X}}=0.75$, s.d.=0.96; Group F3, $\bar{X}=2.75$, s.d.=0.96; $\underline{t}=2.95, d f=14, p<.05)$. 

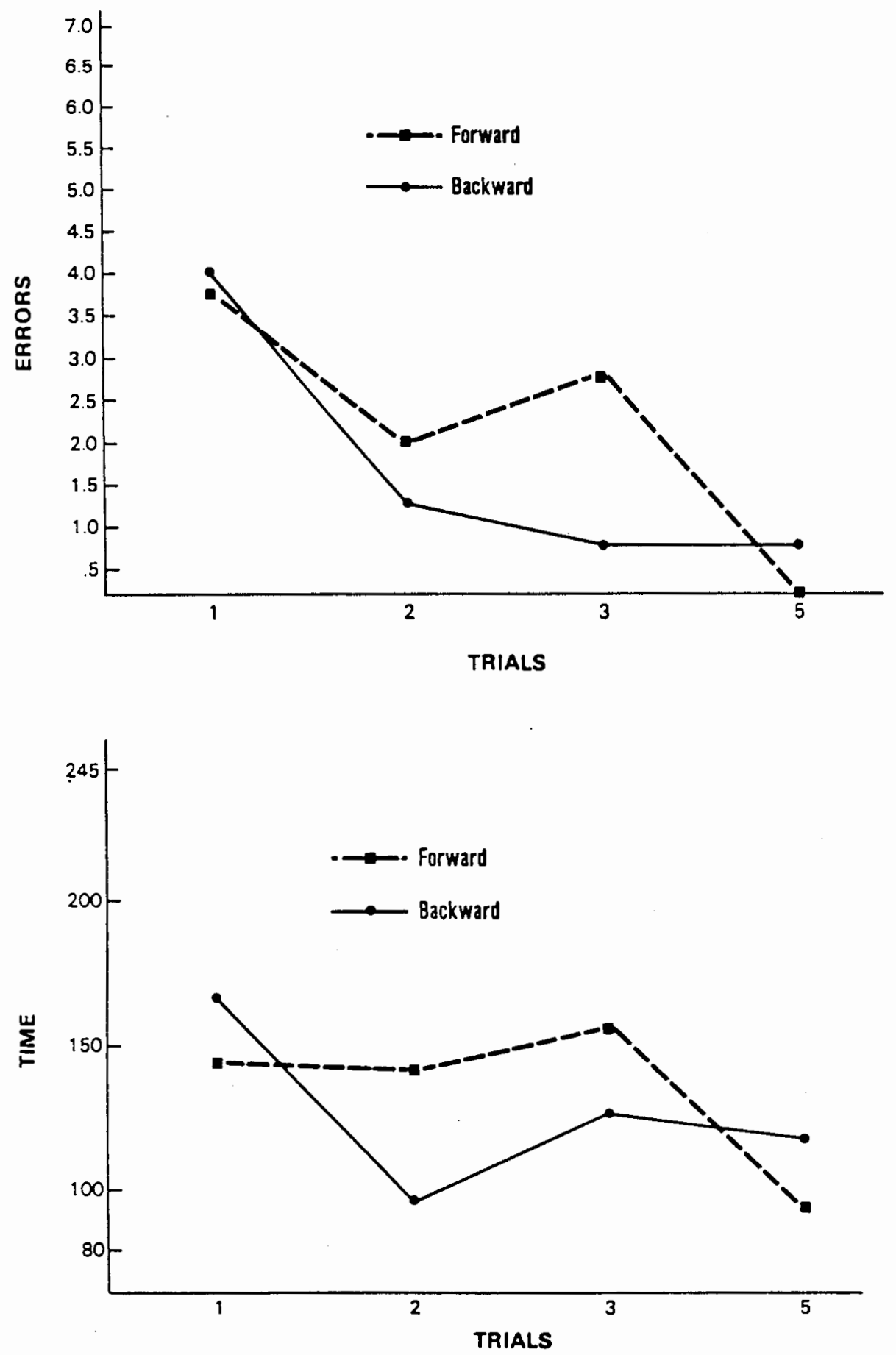

Eigure 4. Graphs highlighting the similarity between the interactive patterns of both measures (Al). 
Summary of results. With minimal exposure to the story, subjects performed poorly overall, but subjects experienced fewer errors with the forward order of presentation. Secondly, with moderate experience, fewer errors and faster solution times were evident, yet with greater success with the backward order of presentation. With extended exposure to the story, subjects' performance became rapid, with little-to-no errors, yet the subjects in the forward condition performed better. 


\section{DISCUSSION}

With minimal practice, subjects in the Forward condition, being exposed to the vignette involving the primary goal (i.e., Part B) last, did better than the subjects in the Backward condition. As noted in the Introduction, early in serial learning, items in a list seem to be bound together by pairwise associations (Paivio \& Csapo, 1969). "Chunking" of the direction choices involved in Part A was partly (or wholely, dependent on the individual's ability) accomplished. Yet with the presentation of Part B and the direction choices that needed to be made, it is likely that this associative process of chunking became overwhelmed. Memory capacity was overloaded, for most, if not all, subjects. Conversely, subjects in the Backward condition on the first exposure were able to chunk some or all of the choices in Part $B$ and then became overloaded and confused when the choice points of Part A were encountered. Consequent1y, in the test situation in which Part A was combined with Part B, the subjects in the Forward condition had a distinct advantage--in terms of being more likely to be cognitively oriented to the situation. In other words, the Forward condition subjects were more likely to have encoded the information necessary for success with Part A, while subjects in the Backward condition were starting the test with the vignette in which they had likely experienced the most confusion (i.e., Part A).

This explanation would account for the significant difference in performance between the two groups exposed once to the problem compo- 
nents. The group exposed to Part A first (Forward Order, One Trial condition [Group FI]) demonstrated fewer errors and less variance inperformance than subjects exposed to Part B first (Backward Order/ One Trial condition [Group B1]).

Measurements of performance for the Forward group who received three readings (Moderate Experience condition) showed that they benefitted from the increased exposure to the problem's parts, but not to the degree realized by the Backward group. This result is consistent with the rationale proposed by Trabasso (1975) as presented in the Introduction. With experience with a problem a spatial representation is formed. Place-learning supercedes pair-wise associations, and being exposed to parts of a problem as they regress from the goal facilitates this process. In other words, the subject gradually constructs from the pairs of responses, an imaginal representation of the entire array of choice responses.

Driesen (1977) showed that people use spatial processes when engaged in logical reasoning. Shaver, Pierson, and Lang (1975) presented a convincing arguement that people tend to use images when possible and this strategy tends to improve problem solving. In other words, this rapid improvement by the Backward group is suggestive of the implementation of those visual/spatial imagery representations. This analysis is consistent with that proposed by (Paivio \& Csapo, 1973), and noted in the Introduction (in terms of the development of an alternate coding system independent of language and expanding shortterm memory).

There was a "ceiling effect" that occured after extended exposure (five trials) in which there were few errors. Time-to-completion 
for those in the Forward condition seemed dependent on motor skills alone, which is congruent with the progression noted by Fitts (1964), as described in the Introduction. Yet, those in the Backward condition with extended practice showed a good deal of variability with regard to performance time. They knew the solution, but were slower responders. It is plausable that those depending on the imaginational tools found it difficult to break set, progressing to a more expedient representational systen, e.g., remembering key alternations.

With minimal practice, the forward condition subjects had fewer errors and faster solution times. With moderate practice, the Backward condition was superior. With a high level of practice the Forward condition was, again, superior, but then such a pattern is consistent with the existence of stages of learning.

The intial superiority of the forward order suggests, in line with the reasoning of Wood regarding the differences in order effects found by DeSoto and Clark, an initial image stage. This would be consistent with the findings of Fitts on an early cognitive stage in which spatial ability is important.

The subsequent superiority of the backward order suggests, in line with the reasoning of Osgood regarding Hull's analysis of Maier's reasoning problem, an associative stage. This would be consistent with the findings of Fitts on an associative stage, following the cognitive stage.

The tendency for the forward order to be superior with high levels of practice is difficult to explain. Fitts postulates a third automatization stage, yet it is difficult to see what implications such a stage might have for order of presentation of problem segments. 
A recommendation for further study would include replicating this experiment with additional data on individual skill level, perhaps as reflected by intelligence, and a variety of problem situations. 


\section{References}

Anderson, B. F. Cognitive Psychology. New York: Academic Press, 1975.

Clark, H. H. Linguistic processes in deductive reasoning. Psychological Review, 1969, 76, 387-404. (a)

Clark, H. H. The influence of language in solving three-term series problems. Journal of Experimental Psychology, 1969, 82, 205-215. (b)

De Soto, C. B., London, M., \& Handel, S. Social reasoning and spatial paralogic. Journal of Personal \& Social Psychology, 1965, $\underline{2}, 513-521$.

Driesen, J. L. A study of the differential effects of visual an auditory presentation on logical reasoning. Unpublished naster's thesis, Portland State University, 1977.

Fitts, P. M. Perceptual-motor skill learning. In A. W. Melton (Ed.), Categories of human learning. New York: Academic Press, 1964.

Griggs, T. M., Townes, J. J., \& Keen, M. S. Processing numerical quantitative information in artificial linear orderings. Journal of Experimental Psychology: Human Learning and Memory, $1979, \underline{5}, 282-291$.

Hul1, C. L. The mechanism of the assembly of behavior segments in novel combinations suitable for problem solution. Psychologica1 Review, 1935, 42, 219-245. 
Hunter, I. M. L. Memory. Baltimore: Penguin, 1957.

Huttenlocher, J. Constructing spatial images: A strategy in reasoning. Psychological Review, 1968, 75, 550-560.

Hunter, I. M. L. The solving of three-term series problems. British Journal of Psychology, 1957, 48, 289-298.

Kendler, H. H., \& Kendler, T. S. Inferential behavior in children:

II. The influence of order of presentation. Journal of Experimental Psychology, 1961, 61, 442-448.

Luria, A. R. The Working Brain. New York: Basic Books, 1973.

Maier, N. R. F. Reasoning in white rats. Comparative Psychology Management, 1929,6 , 1-93.

Miller, G. A. The magical number seven, plus or minus two: Some limits on our capacity for processing information. Psychological Review, 1956, 63, 81-97.

Osgood, C. E. Method and Theory in Experimental Psychology. New York and London: Oxford Univ. Press, 1953.

Paivio, A., \& Csapo, K. Concrete-image and verbal memory codes. Journal of Experimental Psychology, 1969, 80, 279-285.

Paivio, A., \& Csapo, K. Picture superiority in free recall: Imagery or dual coding? Cognitive Psychology, 1973, $5,176-206$. 
Restle, F. Discrimination of cues in mazes: A resolution of the "place-vs.-response" question. Psychological Review, 1957, 64, $217-228$.

Shaver, P., Pierson, L., \& Lang, S. Converging evidence for the functional significance of imagery in problem solving. Cognition, 1975, 4, 359-375.

Trabasso, T. Representation, memory, and reasoning: How do we make transitive inferences? In A. D. Pick (Ed.), Minnesota symposia on child psychology (Vol. 9). Minneapolis: University of Minnesota Press, 1975.

Versteeg, E. B. The influence of order of presentation in the assemb1y of behavior components in a problem solving situation. Unpublished research, Portland State University, 1978.

Wason, P. C., \& Johnson-Laird, P. N. Psychology of reasoning. Cambridge, Massachusetts: Harvard University Press, 1972.

Wood, D. J. The nature and development of problem-solving strategies. Unpublished doctoral dissertation, University of Nottingham, 1969.

Young, R. K. Tests of three hypotheses about the effective stimulus in serial learning. Journal of Experimental Psychology, 1962, $\underline{63}, 307-313$

Youssef, Z. I. Association and integration in serial learning. American Journal of Psychology, 1967, 80, 355-362. 


\section{APPENDIX 1}

\section{INFORMED CONSENT}

I, ject in the research project on The Effect of Order of Presentation and Experience on Problem Solving under the supervision of Edward $B$. Versteeg.

I understand that as a participant I will be asked to combine information involving a character in an adventure story in order to solve a problem presented to the character in the course of the story. The story is presented on a computer monitor. The progression of the story depends on decisions made by me. Within the story are two vignettes, or "mini-stories", in which I direct the travel of the protagonist. In each vignette the protagonist is navigating a cave in which there are decisions to be made as to direction. I will be asked to make, and then enter the decision by pressing the appropriate key on the computer's keyboard. The story continues as I make these responses. The order in which the vignettes are presented will be one of two variables to be manipulated. The other variable is the number of times a subject, like myself, will be allowed to read the vignettes. Following the vignettes, the protagonist is placed in a situation requiring the navigation of both parts of the story. The problem task I will be faced with, then, is to synthesize the direction decisions.

I understand that the possible risks to me are minimal and it will cost me approximately 20 minutes of my time.

It has been explained to me that the purpose of the study is to learn how performance in solving problems is influenced by the order of presentation and the amount of experience with parts to a problem situation.

Mr. Versteeg has offered to answer any questions I may have about the study. I have been assured that all information I give will remain anonymous.

I may not receive any direct benefit from participation in this study, but my participation may help to increase knowledge which may benefit others in the future.

I understand that I am free to withdraw form participation in this study at any time without jeopardizing my grade in any class or my relationship with Portland State University.

I have read and understand the foregoing information.

Date Signature

If you experience any problems that are a result of your participation in this study please contact Director of Spnsored Research, Office of Graduate Studies and Research, Neuberger Hall, Portland State University, 229-3423. 
APPENDIX 2

NARRATIVE GAME PROGRAM/PROBLEM STIMULUS

Jlist $0-570$

5 REM PROBLEM STIMULUS AND SUBJECT RESPONSE PROGRAM

10 HOME : UTAB (2): PRINT TAB! 13);" "PLANE DOWN" "

20 PRINT : PRINT : PRINT TAB! 6) ; A COMPUTER NHARRATION GAME": PRINT

30 VTAB (11): PRINT TAB ( 4) ; "OIRECTIONS: " PRINT : PRINT

40 PRINT TAB( 4); "Read the following story at a"

50 PRINT TAB: 4); "comfortable speed.": PRINT

60 PRINT TAB (4); "Type the appropriate key in"

70 PRINT TAB ( 4);"response to questions.": PRINT

72 FOR $Y=1$ TO 9000 : NEXT $Y$

74 HOHE

76 UTAB (6): PRINT TAB( 4); "For instance, type the "SPACE BAR"

77 PRINT TAB( 4); "to cont inue.": PRINT : PRINT

78 PRINT TAB ( 4); "Type ' $L$ ' for LEFT and ' $R$ ' for RIGHT"

80 PRINT TAB ( 4); "then press the "RETURN" key after"

82 PRINT TAB (4); "choosing 'L' or 'R'." : PRINT : PRINT : PRINT

84 PRINT TAB ( 4); "Relax and most importantly, HAVE FUN!"

90 FOR $Y=1$ TO 9000 : NEXT $Y$

100 HOME

110 READ A

120 IF A = "PAGE 1 " THEN 210

130 IF A = "PAGE 2" THEN 210

140 IF A $=$ "PAGE 3" THEN 210

150 IF A = "PAGE 4" THEN 210

160 IF A $=$ "PAGE 5" THEN 210

170 IF A $=$ "END OF THE COVER STORY" THEN 250

180 SFEED $=150$

190 PRINT A

200 GOTO 110

210 PRINT

220 SPEED $=255$

230 GOSUB 10000

240 GOTO 100

250 GOSUB 10040

500 REM COVER STORY

510 DATA "PLANE DOWN!"

520 DATA " "

530 DATA " "

540 DATA " "

550 DATA "In this narration game you play the part"

560 DATA "of a pilot flying to Rio to pick up",

570 DATA "several corporate executives. There is", 
J1 ist $580-1060$

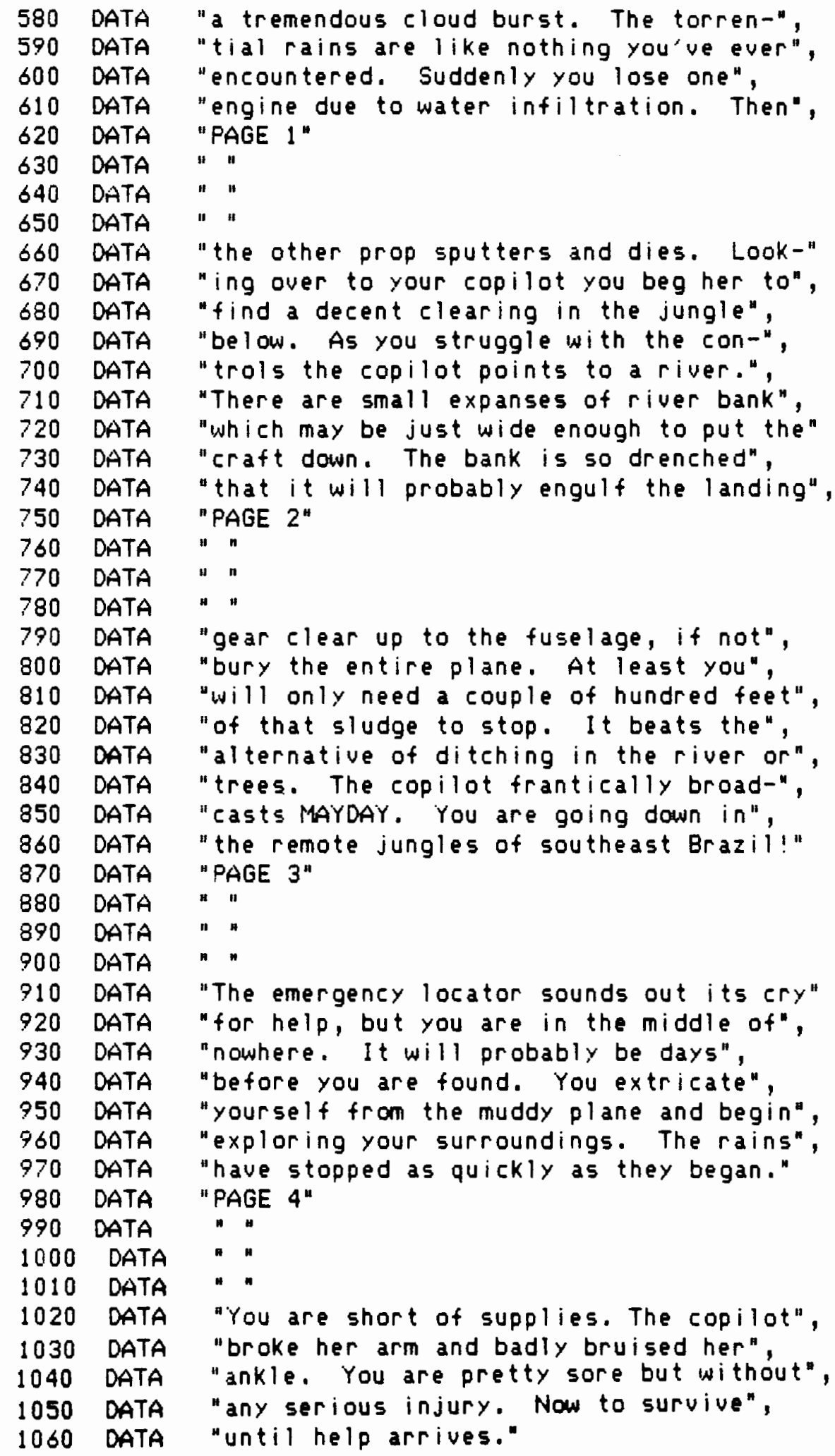


]list $1070-1450$

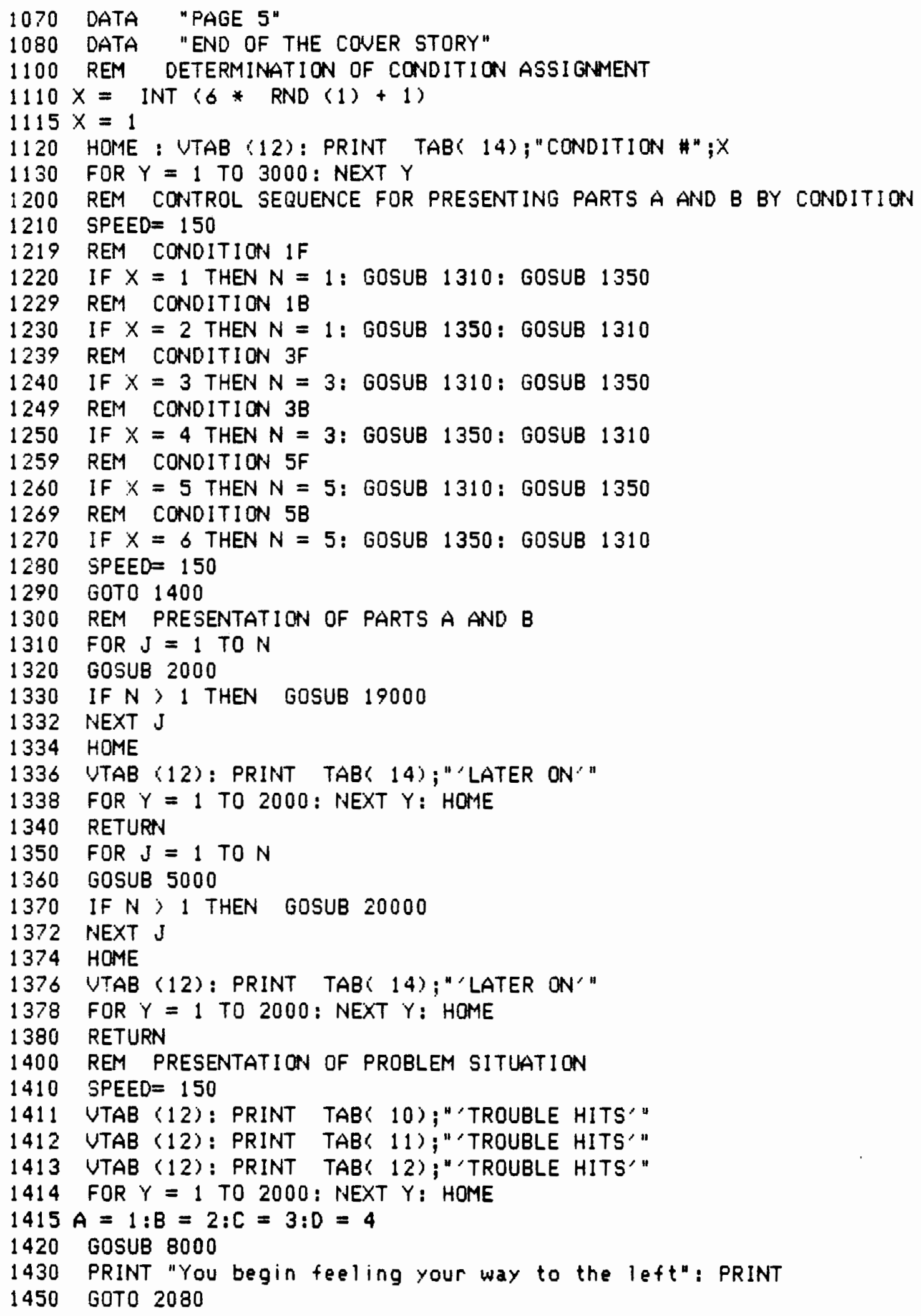


J1 ist $1460-4260$

1460 PRINT "it appears to be the jewel chest!": PRINT

1470 GOSUB 10000

1480 PRINT "Taking a deep breath, you feel along": PRINT

1490 GOTO 5270

1500 SPEED $=255$

1510 GOSUB 17000

1600 END

2000 REM PART A

2010 GOSUB 10040

2020 PRINT "In your wanderings you come across the": PRINT

2030 PRINT "entrance to what appears to be a cave.": PRINT

2040 PRINT "Its a few yards from the river bank, " PRINT

2050 PRINT "just a couple of hundred yards from the": PRINT

2060 PRINT "plane. You part the follage and walk on"

2070 PRINT "inside. Feeling your way to the left": PRINT

2080 PRINT "you find a wall. It has become very": PRINT

2090 PRINT "dark just a few feet from the mouth of"; PRINT

2100 PRINT "the cave. You strike a match."

2110 GOSUB 10000

2120 PRINT "You see that there is a corridor that": PRINT

2130 PRINT "veers to the right and extends at least": PRINT

2140 PRINT "several yards. The mateh burns your": PRINT

2150 PRINT "finger and you let it drop. There": PRINT

2160 PRINT "aren't enough matches to illuminate": PRINT

2170 PRINT "your exploration. Feeling along the": PRINT

2180 PRINT "wall with your left hand, you move ": PRINT

2190 PRINT "cautiously forward.": PRINT

2200 GOSUB 10000

2210 PRINT "Your out-stretched right hand comes": PRINT

2220 PRINT "against what seems to be a wall.": PRINT

2230 GOSUB 14000

2240 GOSUB 10040

2250 PRINT "You go on in the darknezs. inching along"

2260 PRINT "the wall. Your out-stretched right hand"

2270 PRINT "feels a moist wall in front of you.": PRINT

2280 GOSUB 11000

2290 GOSUB 10040

2300 PRINT "Hoving along again you come up against": PRINT

2310 PRINT "another wall.": PRINT

2320 GOSUB 11000

2330 GOSUB 10040

2340 PRINT "Keep on going slowly forward. You bump": PRINT

2350

2360

2370

4200

4210

4220

4230

PRINT "right in to yet another wall.": PRINT

GOSUB 14000

GOSUB 10040

PRINT "Your right foot bumps into something on": PRINT

PRINT "the ground. It makes a hollow wooden": PRINT

4240

PRINT "noise. There is a faint light from": PRINT

4260

PRINT "above. Its an opening in the cavern": PRINT

PRINT "ceiling. Its too dim to see clearly": PRINT

PRINT "it appears to be a chest. This certain-" 
11ist $4265-5340$

4265 IF $A=1$ THEN GOTO 1460

4270 PRINT "Iy is worth a match! Striking the match"

4280 PRINT "you see that indeed it is a chest."

4290 GOSUB 10000

4300 PRINT "It has lettering on the top. It is in": PRINT

4310 PRINT "German. You kick open the lid. Jewels!"

4320 PRINT "Lots of jewels! The match goes out.": PRINT

4330 PRINT "You try to lift the box. Too heauy." : PRINT

4340 PRINT "You stuff your jacket pockets with as" : PRINT

4350 PRINT "many gems as possible. You look again": PRINT

4360 PRINT "at the light from the ceiling.": PRINT

4370 PRINT "You better get back to your partner.": PRINT

4380 PRINT "You can--and will--come back for more": PRINT

4390 PRINT "of the treasure."

4400 GOSUB 10000

4410 RETURN

5000 REM PART B

5010 GOSUB 10040

5020 PRINT "In your wanderings you come across what": PRINT

5030 PRINT "appears to be a hole in the densely": PRINT

5040 PRINT "foliaged ground. How curious! You are": PRINT

5050 PRINT "only a few hundred yards from the plane": PRINT

5060 PRINT "and your partner. Might as well do a": PRINT

5070 PRINT "little exploring. You tie some vines": PRINT

5080 PRINT "together, making certain they are very": PRINT

5090 PRINT "strong. You tie one end to a tree trunk."

5100 PRINT "You drop the other end down the shaft.": PRINT

5110 GOSUB 10000

5120 PRINT "Gingerly, you crawl down. When you": PRINT

5130 PRINT "reach the floor you see the faint out-": PRINT

5140 PRINT "line of a chest to the right. There's": PRINT

5150 PRINT "something slithering over it. You'll": PRINT

5160 PRINT "check that out later! Quickly, you ": PRINT

5170 PRINT "move to the left. It becomes very dark.": PRINT

5180 PRINT "You strike a match. You see that you": PRINT

5190 PRINT "are in a cave. The cavern extends on-": PRINT

5200 PRINT "ward ahead at least several yards.": PRINT

5210 GOSUB 10000

5220 PRINT "The match burns your fingers. You let": PRINT

5230 PRINT "it drop to the ground. There are not": PRINT

5240 PRINT "enough matches to illuminate your ex-": PRINT

5250 PRINT "ploration. Driven by curiousity, you ": PRINT

5260 PRINT "continue on in darkness. Feeling along": PRINT

5270 PRINT "the wall with your right hand you move": PRINT

5280 PRINT "cautiously forward. Your out-stretched": PRINT

5290. PRINT "left hand comes against what seems to be"

5300 PRINT "a wall."; PRINT

5310 GOSUB 14000

5320 GOSUB 10040

5330 PRINT "You go forward in the darkness, very": PRINT

5340 PRINT "carefully. You run up against a wall.": PRINT 
31 ist $5350-9220$

5350 GOSUB 11000

5360 GOSUB 10040

5370 PRINT "Carry on. Moving slowly along, you": PRINT

5380 FRINT "suddenly bump into a wall in front": PRINT

5390 PRINT "of you.": PRINT : PRINT

5400 GOSUB 14000

5410 GOSUB 10040

7000 PRINT "Your right foot bumps into something on": PRINT

7010 PRINT "the ground. It makes a metallic noise.": PRINT

7020 PRINT "This is certainly worth a match! Strik-"

7030 PRINT "ing the match you see that it is a steel"

7040 PRINT "box. It has lettering on the top and": PRINT

7050 PRINT "sides. They are in German. Flipping": PRINT

7060 PRINT "open the latches, you raise the lid.": PRINT

7070 PRINT "Medical supplies and food rations!": PRINT

7080 GOSUB 10000

7090 IF $B=2$ THEN GOTO 1500

7100 PRINT "You strike another match. There is ": PRINT

7110 PRINT "a decent assortment of army rations,": PRINT

7120 PRINT "analgesics, bandages, insulin, epi-": PRINT

7130 PRINT "nepherine, antibiotics, and other medi-": PRINT

7140 PRINT "cines. You stuff your pockets with some"

7150 PRINT "analgesics and a bunch of food. You": PRINT

7160 PRINT "better get back to your partner. You": PRINT

7170 PRINT "can--and will--come back for more food." : PRINT

7180 GOSUB 10000

7190 RETURN

8000 REM TEST SITUATION

8010 GOSUIB 10040

8020 PRINT "Your partner is beginning to act pretty": PRINT

8030 PRINT "strange. Her speech is periodically": PRINT

8040 PRINT "nonsensical. Her color is poor. She": PRINT

8050 PRINT "complains of feeling confused and dizzy."

8060 PRINT "In a moment of lucidity, she reveals": PRINT

8070 PRINT "that she is diabetic. You didn't know!"

8080 GOSUB 10000

8090 PRINT "She becomes faint and then lapses into": PRINT

8100 PRINT "unconsciousness. You"ve got to find her"

8110 PRINT "insulin. She muttered something about": PRINT

8120 PRINT "her flight bag. Frantically rummaging": PRINT

8130 PRINT "through the bag, you find three empty": PRINT

8140 PRINT "uials of insulin. She's exhausted her": PRINT

8150 PRINT "supply!"

8160 GOSUB 10000

8170 PRINT "Suddenly you recall the medicine in the": PRINT

8180 PRINT "steel box. The quickest way to it would"

8190 PRINT "be the shaft, however, its doubtful that"

8200 PRINT "the vines would tolerate another climb-": PRINT

8210 PRINT "ing. No time to take chances. You must"

8220 PRINT "take the route from the mouth of the": PRINT 
Jlist $8230-14036$

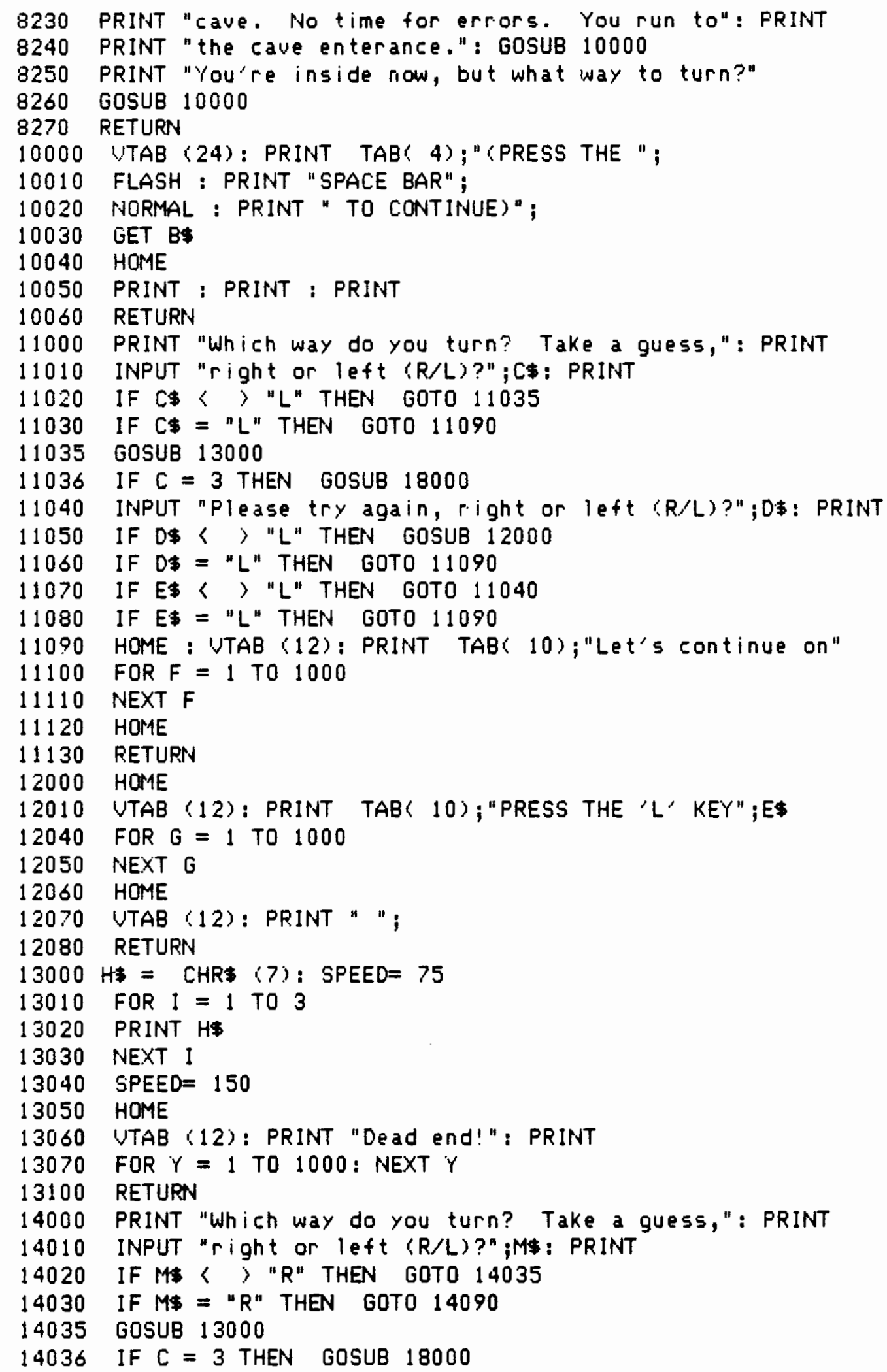


Jlist $14040-$

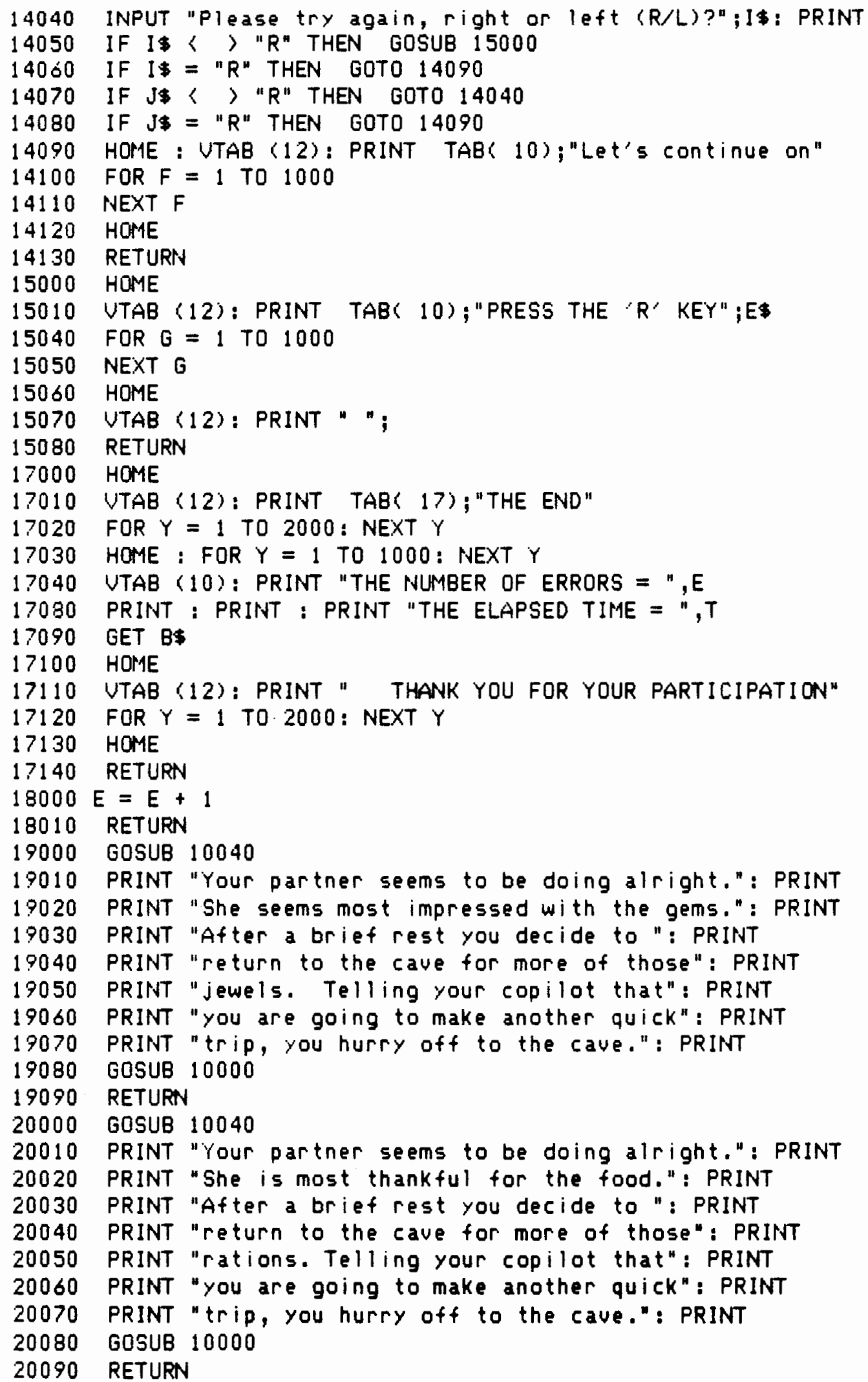




\section{APPENDIX 3}

TEXT OF THE NARRATIVE GAME

PLANE DOWN!

In this narration game you play the part of a pilot flying to Rio to pick up several corporate executives. There is a tremendous cloud burst. The torrential rains are like nothing you've ever encountered. Suddenly you lose one engine due to water infiltration. Then the other prop sputters and dies. Looking over to your copilot you beg her to find a decent clearing in the jungle below. As you struggle with the controls the copilot points to a river. There are small expanses of river bank which may be just wide enough to put the craft down. The bank is so drenched that it will probably engulf the landing gear clear up to the fuselage, if not bury the entire plane. At least you will only need a couple of hundred feet of that sludge to stop. It beats the alternatives of ditching in the river or trees. The copilot frantically broadcasts MAYDAY. You are going down in the remote jungles of southeast Brazil!

The emergency locator sounds out its cry for help, but you are in the middle of nowhere. It will probably be days before you are found. You extricate yourself from the muddy plane and begin exploring your surroundings. The rains have stopped as quickly as they began. You are short of supplies. The copilot broke her arm and badly bruised her ankle. You are pretty sore but without any serious injury. Now to survive until help arrives.

\section{PART A}

In your wonderings you come across the enterance to what appears to be a cave. Its a few yards from the river bank, just a couple of hundred yards from the plane. You part the foliage and walk on inside. Feeling your way to the left you find a wall. It has become very dark just a few feet from the mouth of the cave. You strike a match. You see that there is a corridor that veers to the right and extends at least several yards. The match burns your finger and you drop it to the ground. There aren't enough matches to illuminate your exploration. Feeling along the wall your left hand you move cautiously forward. Your out-stretched right hand comes against what seems to be a wall. Which way do you turn? Take a guess, right or left?

(Several directions choices later...) Your right foot bumps into something on the ground. It makes a hollow wooden noise. There is a faint light from above. Its an opening in the cavern ceiling. Its too dim to see clearly what it is that your foot struck, but it appears to be a chest. This certainly is worth a match! Striking the match you see that indeed it is a chest. It has letterings on the 
top. They are in German. You kick open the 1id. Jewels! Lots of jewels! The match goes out. You try to lift the box. Too heavy. You stuff you jacket pockets with as many gems as possible. You look again at the light from the ceiling. You better get back to your partner. You can--and will-- come back for more of the treasure.

$\underline{\text { PART B }}$

In your wonderings you come across what appears to be a hole in the densely foliaged ground. How curious! You are only a few hundred yards from the plane and your partner. Might as well do a little exploring. You tie some vines together, making cetain they are very strong. You tie one end to a tree trunk. You drop the other end down the shaft. Gingerly, you crawl down. When you reach the floor you see the faint outline of a chest to the right. There's something slithering over it. You'1l check that out later! Quickly you move to the left. It becomes very dark. You strike a match. You see that you are in a cave. The cavern extends onward ahead at least several hundred yards. The match burns your fingers and you drop it to the ground. There aren't enough matches to illuminate your exploration. Feeling along the wall with your right hand you move cautiously forward. Your out-stretched left hand comes against what seems to be a wal1. Which way do you turn? Take a guess, right or left?

(Several direction choices later...) Your right foot bumps into something on the ground. It makes a metallic noise. This certainly is worth a match! Striking the match you see that it is a steel box. It has lettering on the top and sides. They are in German. Flipping open the latches, you raise the 1id. Medical supplies and food rations! You strike another match. There is a decent assortment of army rations, analgesics, bandages, insulin, epinepherine, antibiotics, and other medicines. You stuff your pockets with some analgesics and a bunch of food. You better get back to your partner. You can--and will--cone back for more food.

\section{TEST SITUATION}

Your partner is beginning to act pretty strange. Her speech is periodically nonsensical, her color is poor, she complains of feeling confused and dizzy. In a moment of lucidity, she reveals that she is diabetic. You didn't know! She becomes faint and then lapses into unconsciousness.

You've got to find her insulin. She muttered something about ger flight bag. Rumaging through the bag frantically you find three empty vials of insulin. She's exhausted her supply! Suddenly you recall the medicine in the steel box. The quickest way to it would be the shaft, however, its doubtful that the vines would tolerate another climbing. No time to take chances. You must take the route from the mouth of the cav. No time for errors. You run to the cave enterance.

You are inside now, but what way to turn? 


\section{APPENDIX 4}

\section{DEBRIEFING QUESTIONS FOR EXPERIMENT AI (PILOT STUDY)}

1.) How did you experience the game?

2.) How was the speed at which the words appeared for you?

3.) How did the fact that this was being timed affect you?

4.) How was the story's length--too long, too brief, or alright as is?

5.) What could be done to improve the story?

6.) Any other comments or questions? 


\section{APPENDIX 5}

SUBJECT DATA FOR EXPERIMENT A2

\begin{tabular}{|c|c|c|c|}
\hline SUBJECT \# & CONDITION & ERRORS & TIME \\
\hline 1 & F5 & 0 & 90 \\
\hline 2 & F3 & 2 & 144 \\
\hline 3 & $\mathrm{~F} 1$ & 2 & 122 \\
\hline 4 & F5 & 0 & 98 \\
\hline 5 & B5 & 1 & 110 \\
\hline 6 & B3 & 0 & 130 \\
\hline 7 & $\mathrm{~F} 1$ & 4 & 150 \\
\hline 8 & F1 & 2 & 195 \\
\hline 9 & B3 & 0 & 120 \\
\hline 10 & B5 & 0 & 96 \\
\hline 11 & $\mathrm{~F} 1$ & 3 & 127 \\
\hline 12 & F3 & 2 & 171 \\
\hline 13 & F5 & 0 & 108 \\
\hline 14 & B3 & 2 & 151 \\
\hline 15 & F5 & 0 & 107 \\
\hline 16 & F5 & 0 & 115 \\
\hline 17 & F5 & 0 & 108 \\
\hline 18 & F3 & 3 & 150 \\
\hline 19 & $\mathrm{~F} 1$ & 3 & 127 \\
\hline 20 & F3 & 0 & 134 \\
\hline 21 & F3 & 2 & 116 \\
\hline 22 & $\mathrm{~F} 1$ & 2 & 104 \\
\hline 23 & F5 & 0 & 90 \\
\hline 24 & B3 & 0 & 92 \\
\hline 25 & B3 & 0 & 121 \\
\hline 26 & F5 & 0 & 101 \\
\hline 27 & $\mathrm{~B} 1$ & 5 & 185 \\
\hline 28 & B5 & 2 & 192 \\
\hline 29 & B5 & 0 & 119 \\
\hline 30 & F3 & 2 & 133 \\
\hline 31 & B3 & 0 & 128 \\
\hline 32 & F3 & 5 & 165 \\
\hline 33 & B5 & 0 & 131 \\
\hline 34 & $\mathrm{~B} 1$ & 2 & 156 \\
\hline 35 & B5 & 0 & 141 \\
\hline 36 & B3 & 0 & 130 \\
\hline 37 & F3 & 1 & 126 \\
\hline 38 & $\mathrm{Bl}$ & 4 & 145 \\
\hline 39 & $\mathrm{Fl}$ & 0 & 126 \\
\hline 40 & F5 & 0 & 89 \\
\hline
\end{tabular}




\section{SUBJECT \# CONDITION}

\section{1}

42

43

44

45

46

47

48

49

50

51

52

53

54

55

56

57

58

59

60

TOTALS:

$\mathrm{N}=60$

MEANS:

F3

F1

B1

B1

B1

B5

F1

B1

B5

B1

B1

B3

F1

B1

F3

B3

B5

F5

B5

B3
ERRORS TIME

1

118

121

137

184

135

152

175

117

113

116

101

122

114

$85 \quad 7707$

1

128 
APPENDIX 6

DESCRIPTIVE STATISTICS FOR EXPERIMENT A2

ERRORS:

CONDITION

MEAN

s.d.

var.

MEAN

s.d.

var.

MEAN

s.d.

var.

TIME:

MEAN

s.d.

var.

MEAN

s.d.

var.

MEAN

s.d.

var.

\begin{tabular}{llllll}
\hline F1 & B1 & F3 & B3 & F5 & B5 \\
\hline 2.2 & 3.6 & 1.8 & 0.6 & 0.0 & 0.3 \\
1.14 & 1.43 & 1.48 & 0.97 & 0.0 & 0.67 \\
1.16 & 1.84 & 1.96 & 0.84 & 0.0 & 0.41
\end{tabular}

\begin{tabular}{ccc}
\hline ltrial & 3trials & 5trials \\
\hline 2.9 & 1.2 & 0.15 \\
1.45 & 1.36 & 0.49 \\
1.99 & 1.76 & 0.23
\end{tabular}

\begin{tabular}{cc}
\hline FORWARD & BACKWARD \\
\hline 1.33 & 1.50 \\
1.42 & 1.83 \\
1.96 & 3.25
\end{tabular}

CONDITION

\begin{tabular}{cccccc}
\hline F1 & B1 & F3 & B3 & F5 & B5 \\
\hline 136.0 & 146.4 & 139.4 & 123.4 & 100.7 & 124.8 \\
24.81 & 27.82 & 18.52 & 15.65 & 8.97 & 27.11 \\
554.0 & 696.44 & 308.84 & 220.44 & 72.41 & 661.36
\end{tabular}

\begin{tabular}{rrr}
\hline Itrial & 3trials & 5trials \\
\hline 141.20 & 131.40 & 112.75 \\
26.20 & 18.60 & 23.22 \\
652.26 & 328.64 & 512.09
\end{tabular}

\begin{tabular}{cc}
\hline FORWARD & BACKWARD \\
\hline 125.37 & 131.53 \\
25.28 & 25.67 \\
617.90 & 636.92
\end{tabular}


APPENDIX 7

PARAMETRIC AND NONPARAMETRIC STATISTICS FOR EXPERIMENT A2

ANOVA:

\begin{tabular}{lcc} 
& errors & time \\
\hline order & 0.36 & 0.96 \\
trials & $33.49^{* * *}$ & $7.07^{* *}$ \\
order $x$ trials & $7.41^{* *}$ & $3.51^{*}$
\end{tabular}

Kruskal-Wallis ANOVA:

\begin{tabular}{rll} 
& errors & time \\
\hline UncorrectedH $=$ & $33.319^{* * * *}$ & $25.1420^{* * * *}$ \\
Corrected $\mathrm{H}=$ & $37.8007^{* * *}$ & $25.1531^{* * * *}$
\end{tabular}

Tests specific to the measured number of errors for Experiment A2:

$t$ - tests:
F1 vs. B1
$t=2.39 \quad(\mathrm{p}>.05)$
F3 vs. B3
$t=2.13(\mathrm{p}>.05)$
F5 vs. B5
$t=1.42(\mathrm{p}>.1)$
B1 vs. B3
$t=6.29 \quad(p>.001)$
F1 vs. F3
$t=0.67$ (n.s.)

ANOVA:

\begin{tabular}{lrrrrr} 
Source & \multicolumn{1}{c}{ SS } & d.f. & \multicolumn{1}{c}{ MS } & \multicolumn{1}{c}{ F } & p \\
\hline Total & 156.58 & 59 & & & \\
Order & 0.41 & 1 & 0.42 & 0.36 & n.s. \\
Trials & 77.03 & 2 & 38.52 & 33.49 & $\mathrm{p}<.001$ \\
Order x Trials & 17.03 & 2 & 8.52 & 7.41 & $\mathrm{p}<.01$ \\
Error & 62.10 & 54 & 1.15 & &
\end{tabular}


Scheffe's test:

$F(.05,2,54)=3.23 \quad \mathrm{~ms}$ errors $=1.15$

Forward vs. Backward

$\mathrm{F}=0.075$

1 vs. 3 trials

$\mathrm{F}=5.026 *$

$\mathrm{B} 1$ vs. $\mathrm{F} 1$

$$
F=1.71
$$

3 vs. 5 trials

$\mathrm{F}=1.92$

F3 vs. B3

$$
F=1.25
$$

1 vs. 5 trials

$\mathrm{F}=13.15^{*}$

B5 vs. F5

$$
F=0.078
$$

B1 vs. B3

$$
F=7.82^{*}
$$

$\mathrm{F} 1$ vs. F3

$$
F=0.139
$$

B3 vs. B5

$$
F=0.078
$$

$$
\begin{aligned}
& F 3 \text { vs. } F 5 \\
& F=2.82
\end{aligned}
$$

$\mathrm{B} 1$ vs. B5

$$
F=9.47^{*}
$$

$$
\begin{aligned}
& \mathrm{F} 1 \text { vs. } \mathrm{F5} \\
& \mathrm{F}=4.21 *
\end{aligned}
$$

$\mathrm{K}-\mathrm{W}$ ANOVA:

$$
\begin{array}{rlrl}
\text { UncorrectedH } & =33.319 & & \mathrm{~N}=60 ; \mathrm{k}=6 ; \mathrm{d} . \mathrm{f} .=2 \\
\text { Corrected } \mathrm{H} & =37.8007 & (\mathrm{p}>.001)
\end{array}
$$

Mann-Whitney U test:

$$
\begin{aligned}
& U^{\prime}(F 1 \times B 1)=24 \quad U^{\prime}(F 1 \times F 3)=37.5 \quad U^{\prime}(B 1 \times B 3)=4.5 * \\
& \mathrm{U}^{\prime}(\mathrm{F} 3 \times \mathrm{x} 3)=25 \quad \mathrm{U}^{\prime}(\mathrm{F} 3 \times \mathrm{F} 5)=10^{*} \quad \mathrm{U}^{\prime}(\mathrm{B} 3 \times \mathrm{B} 5)=43.5 \\
& \mathrm{U}^{\prime}(\mathrm{F} 5 \times \mathrm{B} 5)=40 \quad * \mathrm{p}<.02(\mathrm{p}<23 @ .05) \\
& (\mathrm{p}<16 @ .02)
\end{aligned}
$$


Tests specific to the measured time to solution in seconds for Experiment A2:

$t$ - tests:
F1 vs. B1
$\mathrm{t}=0.877$ ( n.s.)
F3 vs. B3
$t=2.17(\mathrm{p}>.05)$
F5 vs. B5
$t=2.65(p>.05)$
$\mathrm{B} 1$ vs. $\mathrm{B} 3$
$t=2.26 \quad(p>.05)$
F1 vs. F3
$t=0.35$ (n.s.)

ANOVA:

\begin{tabular}{lrrrrr} 
Source & \multicolumn{1}{c}{ SS } & d.f. & \multicolumn{1}{c}{ MS } & F & \multicolumn{1}{c}{ p } \\
\hline Total & 45000.85 & 59 & & & \\
Order & 570.42 & 1 & 570.42 & 0.96 & $\mathrm{n} . \mathrm{s}$. \\
Trials & 8355.10 & 2 & 4177.55 & 7.07 & $\mathrm{p}<.01$ \\
Order x Trials & 4154.33 & 2 & 2077.22 & 3.51 & $\mathrm{p}<.05$ \\
Error & 31920.90 & 54 & 591.13 & &
\end{tabular}

Scheffe's test:

$F(.05,2,54)=3.23 \quad$ ms error $=591.1277$

Forward vs. Backward

$$
F=0.193
$$

1 vs. 3 trials

$F=0.325$

$\mathrm{B} 1$ vs. F1

$$
\mathrm{F}=0.183
$$

3 vs. 5 trials

$\mathrm{F}=1.177$

F3 vs. B3

$$
F=0.433
$$

1 vs. 5 trials

$$
\mathrm{F}=2.739
$$

B5 vs. F5

$$
F=0.983
$$

$\mathrm{B} 1$ vs. B3

$$
F=0.895
$$

F3 vs. F1

$$
F=0.020
$$

B5 vs. B3

$$
F=0.003
$$

F3 vs. F5

$$
F=2.534
$$

B1 vs. B5

$$
F=0.789
$$

F1 vs. F5

$$
F=2.10
$$


K-W ANOVA :

$$
\begin{array}{rlrl}
\text { UncorrectedH } & =25.1420 & \mathrm{~N}=60 ; \mathrm{k}=6 ; \mathrm{d} . \mathrm{f} .=2 \\
\text { Corrected } \mathrm{H}=25.1531 & (\mathrm{p}>.001)
\end{array}
$$

Mann-Whittney U test:

$$
\begin{aligned}
& U^{\prime}(F 1 \times B 1)=39 \\
& U^{\prime}(F 3 \times B 3)=26 \\
& U^{\prime}(F 5 \times B 5)=14 * \quad(p<.02)
\end{aligned}
$$


APPENDIX 8

DATA OF EXPERIMENT A1 (PILOT STUDY)

\begin{tabular}{|c|c|c|c|}
\hline SUBJECT \# & CONDITION & ERRORS & TIME \\
\hline 1 & F1 & 2 & 168 \\
\hline 2 & F3 & 2 & 129 \\
\hline 3 & $\mathrm{~F} 1$ & 4 & 144 \\
\hline 4 & B3 & 2 & 161 \\
\hline 5 & B5 & 0 & 131 \\
\hline 6 & F1 & 6 & 137 \\
\hline 7 & F2 & 3 & 135 \\
\hline 8 & B2 & 0 & 75 \\
\hline 9 & B3 & 0 & 122 \\
\hline 10 & B5 & 0 & 78 \\
\hline 11 & B1 & 5 & 175 \\
\hline 12 & B1 & 2 & 92 \\
\hline 13 & F5 & 0 & 102 \\
\hline 14 & F5 & 0 & 79 \\
\hline 15 & $\mathrm{~F} 2$ & 3 & 270 \\
\hline 16 & B2 & 2 & 110 \\
\hline 17 & B3 & 1 & 82 \\
\hline 18 & F3 & 4 & 175 \\
\hline 19 & F1 & 3 & 126 \\
\hline 20 & B1 & 5 & 270 \\
\hline 21 & F3 & 3 & 148 \\
\hline 22 & F5 & 0 & 83 \\
\hline 23 & F2 & 2 & 73 \\
\hline 24 & B3 & 0 & 128 \\
\hline 25 & F5 & 0 & 112 \\
\hline 26 & B5 & 2 & 128 \\
\hline 27 & $\mathrm{~B} 1$ & 4 & 133 \\
\hline 28 & F2 & 0 & 93 \\
\hline 29 & B2 & 2 & 96 \\
\hline 30 & B2 & 1 & 104 \\
\hline 31 & B5 & 1 & 123 \\
\hline 32 & F3 & 2 & 171 \\
\hline
\end{tabular}

TOTALS:

$\mathrm{N}=32$

MEANS:

$61 \quad 4153$

$1.90 \quad 129.78$ 


\section{APPENDIX 9}

DESCRIPTIVE STATISTICS FOR EXPERIMENT AI (PILOT STUDY)

ERRORS:

CONDITION

\begin{tabular}{llllrrrrr} 
& F1 & B1 & F2 & B2 & F3 & B3 & F5 & B5 \\
\cline { 2 - 8 } MEAN & 3.75 & 4.0 & 2.0 & 1.25 & 2.75 & 0.75 & 0.0 & 0.75 \\
s.d. & 1.71 & 1.41 & 1.41 & 0.96 & 0.96 & 0.96 & 0.0 & 0.96 \\
var. & 2.19 & 1.5 & 1.5 & 0.69 & 0.69 & 0.69 & 0.0 & 0.69
\end{tabular}

\begin{tabular}{lrccc} 
& 1trial & 2trials & 3trials & 5trials \\
\cline { 2 - 5 } MEAN & 3.88 & 1.63 & 1.75 & 0.38 \\
s.d. & 1.46 & 1.19 & 1.39 & 0.74 \\
var. & 1.86 & 1.23 & 1.69 & 0.48
\end{tabular}

\begin{tabular}{rcc}
\cline { 2 - 3 } MEAN & FORWARD & BACKWARD \\
s.d. & 2.13 & 1.69 \\
var. & 1.78 & 1.70 \\
& 2.98 & 2.71
\end{tabular}

TIME:

CONDITION

\begin{tabular}{lrrrrrrrr} 
& \multicolumn{1}{c}{ F1 } & \multicolumn{1}{c}{ B1 } & \multicolumn{1}{c}{ F2 } & \multicolumn{1}{c}{ B2 } & \multicolumn{1}{c}{ F3 } & \multicolumn{1}{c}{ B3 } & F5 & B5 \\
\cline { 2 - 8 } MEAN & 143.75 & 167.5 & 142.75 & 96.25 & 155.75 & 123.25 & 94.0 & 115.0 \\
s.d. & 17.78 & 76.27 & 88.68 & 15.28 & 21.44 & 32.41 & 15.64 & 24.89 \\
var. & 237.19 & 4363.3 & 5898.2 & 175.19 & 344.69 & 787.69 & 183.5 & 464.5
\end{tabular}

\begin{tabular}{lrccc}
\cline { 2 - 5 } MEAN & 1trial & 2trials & 3trials & 5trials \\
\cline { 2 - 5 } s.d. & 155.63 & 119.5 & 139.5 & 104.5 \\
var. & 52.82 & 63.94 & 30.8 & 22.28 \\
& 2441.23 & 3577.25 & 830.25 & 434.25
\end{tabular}

\begin{tabular}{rrc}
\cline { 2 - 3 } MEAN & FORWARD & BACKWARD \\
\cline { 2 - 3 } s.d. & 134.06 & 125.5 \\
var. & 48.74 & 47.68 \\
& 2227.06 & 2131.38
\end{tabular}


APPENDIX 10

PARAMETRIC AND NONPARAMETRIC STATISTICS FOR EXPERIMENT A1

ANOVA:

\begin{tabular}{lcc} 
& errors & time \\
\hline order & 1.25 & 0.31 \\
trials & $13.81 * * *$ & 2.1 \\
order x trials & $2.41 *$ & 1.37
\end{tabular}

Kruska1-Wallis ANOVA:

\begin{tabular}{ccc} 
& errors & time \\
\hline UncorrectedH $=$ & $19.614^{* * *}$ & $13.105^{* * *}$ \\
Corrected $H=$ & $20.771^{* * *}$ & $13.112^{* *}$
\end{tabular}

$t$ - tests:

Condition

$\begin{array}{lll}\text { F1 vs. B1 } & \text { errors } & \text { time } \\ \text { F2 vs. B2 } & 0.226 & 1.494 \\ \text { F3 vs. B3 } & 0.938 & 1.632 \\ \text { F5 vs. B5 } & 2.946^{*} & 0.565 \\ \text { B1 vs. B2 } & 3.562 & 0.629 \\ \text { B1 vs. B3 } & 3.812^{* *} & 1.568 \\ \text { B1 vs. B5 } & 3.812^{* *} & 1.059 \\ \text { F1 vs. F2 } & 1.579 & 1.281 \\ \text { F1 vs. F3 } & 1.020 & 1.568 \\ \text { F1 vs. F5 } & 4.387^{* *} & 0.263 \\ \text { B2 vs. B3 } & 0.528 & 0.181 \\ \text { B2 vs. B5 } & 0.528 & 0.956 \\ \text { F2 vs. F3 } & 1.105 & 0.658 \\ \text { F2 vs. F5 } & 2.946^{*} & 1.474 \\ \text { B3 vs. B5 } & 0.000 & 0.362 \\ \text { F3 vs. F5 } & 4.050^{* *} & 0.437\end{array}$

Mann-Whitney U test:

Condition

F1/B1

$\mathrm{F} 2 / \mathrm{B} 2$

$\mathrm{F} 3 / \mathrm{B} 3$

$\mathrm{F} 5 / \mathrm{B} 5$

$\mathrm{Fl} / \mathrm{F} 3$

F3/F5

$\mathrm{B} 1 / \mathrm{B} 3$

B3/B5

errors

$\begin{array}{ll}7 & 7 \\ 4.5 & 7 \\ 1 & 2 \\ 4 & 4 \\ 4 & 4 \\ 2 & 0 \\ 0 & 4 \\ 6.5 & 7.5\end{array}$


Scheffe's test:

Condition

Forward/Backward

1 tria1/2trials

1 trial/3trials

1 trial/5trials

2trials/3trials

2trials/5trials

3trials/5trials

$\mathrm{B} 1 / \mathrm{F} 1$

$\mathrm{B} 2 / \mathrm{F} 2$

F3/B3

$\mathrm{B} 5 / \mathrm{F} 5$

$\mathrm{B} 1 / \mathrm{B} 2$

$\mathrm{B} 1 / \mathrm{B} 3$

$\mathrm{B} 1 / \mathrm{B} 5$

$\mathrm{B} 2 / \mathrm{B} 3$

$\mathrm{B} 2 / \mathrm{B} 5$

B3/B5

$\mathrm{F} 1 / \mathrm{F} 2$

F1/F3

F1/F5

F2/F3

F2/F5

$\mathrm{F} 3 / \mathrm{F} 1$

F3/F5

$F(.05,2,24)=3.40$

errors

0.44

2.25

2.13

$3.5 *$

0.12

1.25

1.37

0.25

0.75

2.0

0.75

2.75

2.75

3.25

0.5

0.5

0.0

1.75

1.0

$3.75 \%$

0.75

2.0

$\overline{2.75}$

2.75

C. diff. for error $=3.27$

C. diff. for time $=129.73$
8.56

36.13

16.13

51.13

20.0

15.0

35.0

23.75

46.5

32.533

21.0

71.25

44.25

52.5

27.0

18.75

8.25

1.0

49.75

13.0

48.75

12.0

61.75

$(" * * 1 "=p>.05)$

("**" $=\mathrm{p}>.01)$

$(" * * * "=p>.001)$ 